Dorothea Rebecca Schönsee*

\title{
Schattenfiguren, Spektren, Gespenster als leuchtende Verheißung. Simon Kronbergs Sonderstellung in der deutschen Literatur des Expressionismus
}

https://doi.org/10.1515/naha-2019-0002

Published online September 25, 2020

\begin{abstract}
Der Artikel untersucht den originären Beitrag Simon Kronbergs zur deutschen Literatur des Expressionismus. Der zu den „vergessenen und verkannten Autoren der expressionistischen Generation” (Lützeler) gehörende Kronberg ist bis heute kaum untersucht. Als Sohn jüdisch-galizischer Zuwanderer 1891 in Wien geboren, studiert er 1913 bei Emile Jacques-Dalcroze, dessen Lichtund Bewegungschoreographien ihn nachhaltig prägen. Weitere Stationen sind Düsseldorf bei dem Schauspieler-Paar Lindemann/Dumont, München und Berlin. 1934 emigriert er nach Palästina, wo er 1947 stirbt. Seine Texte entwerfen eine Sprache, deren sinnstiftende Bilder von seiner biographischen Erfahrung geprägt sind und jüdische Mystik, Tanz und Rhythmus auf spezifische Weise integrieren. Im Zentrum steht Kronbergs Konzeption des Schattens als einer Möglichkeit der Wandlung des Menschen in einer Welt der Rationalität und der Entkopplung des täglichen Lebens von Körper und Sinnlichkeit hin zu einer Erfahrung des Lichts. Am Beispiel seiner Erzählung “Chamlam” zeigt der Beitrag, dass seine Schattenfiguren in einem beachtenswerten Spannungsverhältnis zum Diskurs der Gespenster im Expressionismus stehen.
\end{abstract}

Keywords: poetry, genre theory, theory of form, theory of fragments, Simon Kronberg, jüdische Mystik, Expressionismus, Gespenster, Schatten

\footnotetext{
*Corresponding author: Dorothea Rebecca Schönsee, Institut für Germanistik, Neuere deutsche Literatur, Universität Wien Philologisch-Kulturwissenschaftliche Fakultät, Wien, Austria, E-mail: dorothea.rebecca.schoensee@univie.ac.at. https://orcid.org/0000-0002-7438-2086
} 


\section{Einleitung}

Simon Kronbergs (1891-1947) eigenwillige Texte haben immer wieder kurz Beachtung gefunden. ${ }^{1}$ Dennoch hat die Feststellung Paul Michael Lützelers, dass es sich bei Kronberg um einen vergessenen und verkannten Autor der expressionistischen Generation handelt, bis heute seine Gültigkeit, ${ }^{2}$ wenngleich sich erste Schritte hin zu einer stärkeren künstlerischen wie wissenschaftlichen Rezeption abzeichnen. ${ }^{3}$ Gerade Kronbergs Schattenfiguren nehmen eine interessante Sonderstellung in der Literatur des Expressionismus ein. Die Figur des Doppelgängers ebenso wie die des Gespenstes werden neu konfiguriert. Er führt sie aus Erfahrungen der Leere einer Sprache zu, die über Metaphern des Lichts, aber auch der Bedeutung des Klangs als leuchtende Verheißung und Ausweg aus einer drükkenden Gegenwart verstanden wird. Unkörperliches wird rückgebunden an eine bewegungsgeleitete Körperlichkeit, die das Individuum als sinnliches Wesen in der Gemeinschaft neu bestimmen soll. Dabei nutzt er kabbalistische Symbole, um den Aufstieg der Schatten in das Licht als Neues Jerusalem zu gestalten.

Die folgende Analyse untersucht Kronbergs Lyrik und seine Erzählung „Chamlam“ (1921) ${ }^{4}$ im Hinblick auf seinen performativen Expressionismus, der die

1 Vgl. Karl Otten, „Das Werk Simon Kronbergs“, Bulletin des Leo Baeck Instituts 4 (1961), 101-110. Otten veröffentlichte Kronberg zudem in den Anthologien Schrei und Bekenntnis. Expressionistisches Theater (Luchterhand: Neuwied am Rhein 1959), Das leere Haus. Prosa jüdischer Dichter (Stuttgart: Cotta 1959), Schofar. Lieder und Legenden jüdischer Dichter (Luchterhand: Neuwied am Rhein 1962) und Ego und Eros. Meisterzählungen des Expressionismus (Stuttgart: Goverts 1963); dennoch stießen seine Bemühungen um die Verbreitung der Texte auf wenig bis keine Resonanz. Seit 1993 liegt eine Werkausgabe vor, die zum Großteil bis dahin unveröffentlichte, aus den beiden Teilnachlässen (DLA; APK) edierte Texte enthält: Simon Kronberg, Werke, hrsg. v. Armin A. Wallas, 2 Bd., Bd. 1: Lyrik - Prosa; Bd. 2: Dramatik (München: Klaus Boer Verlag, 1993).

2 Paul Michael Lützeler, „Wachsende Kraft. Simon Kronberg, ein vergessener Exilautor“, Neue Zürcher Zeitung, 11. März 1994, abgedruckt in: Mnemosyne. Zeitschrift für jüdische Kultur 30 (2006), 141-143: 142.

3 Zum Beispiel in der Aufführung von Simon Kronbergs „Nittel-Blinde Nacht“ (1941) aus seinem Spätwerk, im Theater Arche in Wien, im Dezember 2019. Eine ausführliche Kritik bietet Michaela Mottinger: „Statt Weihnachtslieder hallt Progromgeschrei“, Mottingers-Meinung.at. Die OnlineKulturzeitschrift (Blog), 23. Dezember 2019, http://www.mottingers-meinung.at/?p=37070 [27.01. 2020]. Ebenso ist hier Daniel Hoffmanns Essay zu Simon Kronberg zu nennen und dessen Ausführungen zur liturgischen Dimension von Kronbergs Texten: Daniel Hoffmann, Religiöse Turbulenzen. Essays zur literarischen Darstellung des Religiösen im 20. Jahrhundert (Würzburg: Königshausen \& Neumann, 2019), 61-62 u. 113-141, sowie zu Kronbergs performativen Expressionismus: Rebecca Schönsee, „,Opfer, atemloser Wege, blind“ - Getanzte Gebete aus verbranntem Lachen. Zur Lyrik Simon Kronbergs“, Expressionismus 2 (2015), 97-115.

4 Simon Kronberg, „Chamlam“, in: ders., Werke I, 133-179 (zuerst erschienen in: Verlag der Dichtung Gustav Kiepenhauer, 1921). 
Frage von Wirklichkeit und Gespenst neu stellt und hierfür auf besondere Weise Bilder jüdischer Mystik nutzt. Dabei möchte ich aufzeigen, dass Kronberg poetische Gegenorte bildet, die seinen Erfahrungen von Zerfall und Zerstörung eine mögliche Erlösung entgegensetzen. Das Element des Tanzes ist für ihn hierbei ebenso zentral wie die Figur des Schattens als Teil einer grotesken Realitätsbeschreibung und Intervention. Seine Schattenfiguren sind gekennzeichnet von seiner autobiografischen Erfahrung als Dichter und Tänzer in Wien und Hellerau, als Jude und Flüchtling, der 1934 von Berlin in ein Kibbuz nach Palästina emigrierte. Den zentralen Bestandteil dieser Untersuchung bietet Kronbergs Auseinandersetzung mit einer weiblichen Leitfigur. Sie ist eine Allegorie der Weisheit und der leuchtenden Verheißung göttlich-mystischer Erfahrung.

\section{Gespenstergeschichten und Schattenfiguren: Überblick und Kontrapunkt zu Simon Kronberg}

Im Folgenden werde ich zunächst kurz drei typische Gespenstergeschichten umreißen, die den Gegensatz zu Simon Kronberg konfigurieren. Denn gerade am Beispiel der Gespenster lässt sich Kronbergs besondere, eigene Poetik zeigen. Im Diskurs der Gespenster arbeitet die Literatur des Expressionismus den Einbruch der Maschinen in eine bürgerliche Welt und den damit verbundenen Wandel auf.

„Gespenster [...] sind so wenig Wesen, wie die abgelegte Schlangenhaut ein Körper ist“, 5 erklärt Oscar A. H. Schmitz in seiner 1912 erschienenen „Gespenstergeschichte”. Sein Gespenst, Lynx, ist laut Erzähler ein „Seelenrest“, ${ }^{6}$ der sich erweitern kann, wenn es sich mit einer verlorenen Seele verbindet und sich in eine Hülle einfügt. Bei Schmitz bietet Herr von Pepinster eine solche Hülle für das Gespenst, „plötzlich war es in seine Kleider gefahren und hatte von dem ganzen Wesen Besitz ergriffen, ohne daß dieses sich auch nur gewehrt hätte. “7 Bei Schmitz übernimmt das Gespenst mehr und mehr das fremde Leben des urbanen Spaziergängers und fühlt sich symbolisch in das Leben der Stadt ein. Das Gespenst wird im Laufe der Erzählung zu seinem Doppelgänger. In „Herr von Pepinster und sein Popanz“, so der volle Titel der Erzählung, haben die Protagonisten die Rollen getauscht: Pepinster wird zur Schreckgestalt und zum Popanz. Er stellt sich an die Stelle der Vogelscheuche, die Lynx anfänglich als Einstieg in die Maske genutzt hatte. Durch diesen Tausch wird die Ordnung scheinbar wiederhergestellt: „Und

5 Oscar H. A. Schmitz, „Herr von Pepinster und sein Popanz. Eine Gespenstergeschichte“, Neue Rundschau 23 (1912), 1709-1723: 1709.

6 Ebd.

7 Ebd., 1710. 
niemand weiß von der ganzen Geschichte, denn äußerlich ist nichts passiert. “8 Damit bedient Schmitz eine typische Trope des Expressionismus: Pepinster wird, was er aus expressionistischer Sicht schon immer war: lebendig tot. ${ }^{9}$ In der Trennung durch das Gespenst von sich selbst und seiner Verdoppelung wird er stillgestellt: Es ist für das gespenstische Gefühl der Expressionisten und für ihre Stellung zur Großstadt eine repräsentative Geschichte: Von den Protagonisten bleiben nur Fratzen und Hüllen zurück.

In der Erzählung von Döblin „Die Tänzerin und der Leib“ $(1904 / 1911)^{10}$ siegt das Mechanische, Kühle. Das Gespenstische der Krankheit, bei Döblin Zeichen für einen Rest von Menschlichkeit, wird aus der Welt getilgt. Die Tänzerin - das zur Puppe geformte Ballettmädchen - trennt sich ganz von ihrem Leib. Noch im Leben wird sie zum Gespenst, das schließlich den von Krankheit gezeichneten Leib durch Selbstmord umbringt; während es ihr früher gelang, „über den üppigsten Tanz Kälte zu sprühen“, ${ }^{11}$ tötet sie den früh siechenden Leib, den sie nun als „träges Tier“"12 von sich abtrennt.

Wie einstmals [...] wollte sie ihren Willen wieder fühlen. Sie wollte einen Walzer, einen wundersüßen, mit ihm tanzen, der ihr Herr geworden war, mit dem Leib. Mit einer Bewegung ihres Willens konnte sie ihn noch einmal mit den Händen fassen, den Leib, das träge Tier, ihn hinwerfen, herumwerfen, und er war nicht mehr der Herr über sie. Ein triumphierender Haß wühlte sie von innen auf; [...]. Noch im Tode hatte die Tänzerin den kalten, verächtlichen Zug um den Mund. ${ }^{13}$

Döblin zeichnet hier eine Allegorie der Mechanisierung als kalte Verführung, die alles Sinnliche inkorporiert, letztlich aber tötet.

Der Tänzerin Ella als einem mechanischen, kalten Gespenst stehen expressionistische Gestalten gegenüber, wie z. B. Albert Ehrensteins Tubutsch. ${ }^{14}$ Dieser ist ein Mensch, der seinen Verfall annimmt und erkennt: „Um mich, in mir herrscht die Leere, die Öde, ich bin ausgehöhlt und weiß nicht wovon. “15 Die industrielle

8 Ebd., 1723.

$9 \mathrm{Zu}$ dieser Thematik vgl. den gleichnamigen Abschnitt bei Wolfgang Rothe, Der Expressionismus. Theologische, soziologische und anthropologische Aspekte einer Literatur (Frankfurt a. M.: Vittorio Klostermann, 1977), 432-447.

10 Alfred Döblin, „Die Tänzerin und der Leib“, in: Die Ermordung einer Butterblume. Ausgewählte Erzählungen. 1910-1950, hrsg. v. Walter Muschg (Olten/Freiburg i. Breisgau: Walter, 1962), 17-21.

11 Ebd., 17 und 20.

12 Ebd., 20.

13 Ebd., 20-21.

14 Albert Ehrenstein, „Tubutsch“, in: ders., Tubutsch. Mit 12 Zeichnungen von Oskar Kokoschka (Wien/Leipzig: Jahoda und Siegel, 1911), 11-62.

15 Ebd., 13; vgl. hierzu auch Rothe, Expressionismus, 123. 
Welt der Puppen im „Spiel des straffen Leibes“, ${ }^{16}$ wie sie Döblin zeichnet, sehnt sich nach einer Wirklichkeit, die die Hüllen überwindet. Sie weiß aber auch: Für die romantischen Gespenster ist kein Platz mehr. ${ }^{17}$ Die technizistische Wirklichkeit blickt fratzenhaft, gespenstisch in den Traum einer Welt, die es nicht mehr gibt. Für den Einzelnen gilt jenes Gefühl, das Ehrensteins Tubutsch formuliert: „Allein irre ich in der großen Stadt umher. Niemand schenkt mir Beachtung. "18 Der Absturz ins Nichts, ${ }^{19}$ in die „Tubutsch-Welt der Öde“ ${ }^{20}$ ist radikal hoffnungslos: Karl Tubutsch fürchtet, dass „selbst der Tod, den er als letzten Ausweg aus der Öde, Langeweile und Tristesse des Alltags in Erwägung zieht“, ihn „noch enttäuschen“ ${ }^{21}$ könnte. Die Texte Kronbergs unterscheiden sich grundlegend von diesen Beispielen, indem er Formen des Alltäglichen produktiv nutzt und die Angst vor der Schattenwelt überwindet. Seine Aufhebung ist die Groteske.

Die Stadt des Expressionismus wird zu einem Angst-Gespenst. Der Einzelne als Zerrissener in der einsamen Masse, im Moloch der Stadt, fühlt sich als Gespenst in der Entfremdung. ${ }^{22}$ Martin Buber gibt diesem Problem in seinem „Gespräch über der Stadt“, einem unter dem Titel Daniel. Gespräche von der Verwirklichung ${ }^{23}$ publizierten Dialog, eine andere Wendung. Das Thema der „Verwirklichung“, das Buber im Zuge eines Versuchs der Erneuerung später insbesondere durch seine Lektüre des Chassidismus diskutiert, wird nicht nur Simon Kronberg aufgreifen, sondern zeigt sich ebenso bei anderen Expressionisten, beispielhaft etwa bei Else Lasker-Schüler, ${ }^{24}$ die Kronberg sehr

16 Döblin, Tänzerin, 17.

17 Wie es bereits Oscar Wilde in The Canterville Ghost zeigt, s. Oscar Wilde, „The Canterville Ghost“, in: Lord Arthur Savile's Crime and Other Prose Pieces, hrsg. v. Robert Ross (London: Methuen, 1908), 65-119.

18 Ehrenstein, Tubutsch, 23.

19 Armin A. Wallas, „Nachwort“, in: Texte des Expressionismus. Der Beitrag jüdischer Autoren zur österreichischen Avantgarde, hrsg. v. Armin A. Wallas (Wien: edition neue Texte, 1988), 279-296: 290 (im Folgenden zit. als Wallas, Nachwort Expressionismus).

20 Ebd.

21 Ebd.

22 Zur Strukturkrise des modernen Ich zwischen „Ichdissoziation und Aufbruchstimmung“ als kennzeichnende Thematik des Expressionismus siehe: Silvio Vietta u. Hans-Georg Kemper, Expressionismus, 2. bibliogr. erg. Aufl. (München: Fink, 1983), 25.

23 Martin Buber, „Von der Wirklichkeit. Gespräch über der Stadt“, in: ders., Daniel. Gespräche von der Verwirklichung (Leipzig: Insel, 1913), 25-54.

24 Insbesondere in ihrer Betonung eines aktiven Teilnehmens an einer religiös-mystischen Erlebnis-Botschaft entsprechend der „Spontaneität und feierlichen Freude des chassidischen Lebensethos“, s. Anya Mali, „Dichtung als Gebet. Mystik und Mystagogie bei Else Lasker-Schüler“, Zeitschrift Für Religions- und Geistesgeschichte 41.2 (1989), 146-165: 149. 
bewunderte. ${ }^{25}$ Kronberg wird vor dem Hintergrund seiner autobiografischen Erfahrungen die Vision einer mystisch inspirierten (Selbst-)Verwirklichung als Basis eines gemeinschaftlichen Lebensethos auf besondere Weise in seine Dichtung integrieren. Bubers Daniel beschreibt die Stadt als „gesetzlose[n] Tanz der Gespenster“: Er wünscht sich: „Könnte ich doch diese Gespenster zur Wirklichkeit erlösen!“26 Erst wer im Leben den Tod begreift, kann demnach die Erstarrung der zweckgebundenen Welt von Geld und Macht überwinden, kann die „Landkarte des Himmels und der Erde“ ${ }^{\text {27 }}$ in ihrer Verbindung zum Geist als Weltseele finden. Buber zeigt, wie das Gespensterbewusstsein als schattenloses, totgestelltes Leben die Wirklichkeit verliert.

Aus dem Gefängnis der Welt, in dem die Menschen zu Hüllen werden, in der das Gespenstische als Spiegel ihrer Erstarrung wütet, ${ }^{28}$ gewinnt analog zum Gespenst der Schatten im Großstadtexpressionismus als weiterer Doppelgänger ein „Zweites Gesicht“. ${ }^{29}$ Insbesondere das Medium der Lyrik in seinen Verdichtungsprozessen reflektiert das Gespenstische im Bild des Schattenhaften. Der Schatten wird zum Ausdruck der Überlagerung und der Superposition von Sichtbarem und Unsichtbarem. ${ }^{30}$ Buber diskutiert im Gespräch die Erfahrung der Polarität, von Identität und Subjektverlust, Leben und Hülle. Das Bild des Schattens, der den vereinsamten Vagabunden auf seinem „Herbstnächtlichen Gang” durch die sündige Umgebung begleitet, wie ihn Oskar Kanehl 1914 beispielhaft beschreibt, kehrt in einer Vielzahl expressionistischer Texte wieder:

25 Armin A. Wallas, „Nachwort. ,Ein Jude und ein Dichter dazu“ - Simon Kronberg“, in: Kronberg, Werke, Bd. 2: Dramatik, 355-410: 365 (im Folgenden zit. als Nachwort).

26 Buber, Daniel, 53; zum „Gespenstigen des Lebens“ siehe auch: Rothe, Expressionismus, 122.

27 Buber, Daniel, 52.

28 Rothe erläutert die „Deprivation des Menschen zum Schemen und Gespenst, zum Spuk“ (Expressionismus, 436): „Als Schatten, Schemen und Scheinwesen ist der Mensch von jeder Wirklichkeit entleert, der leere und nichtige Mensch“ (ebd., 439).

29 Gero von Wilpert, Die Deutsche Gespenstergeschichte. Motiv, Form, Entwicklung (Stuttgart: Alfred Kröner, 1994), 364.

30 So übernimmt gewissermaßen die Dichtung sogar die „Aufgabe“ der herkömmlichen Gespenstergeschichte, wie sie von Wilpert über die Epochen nachverfolgt. Er zeigt, wie der „lyrische Schatten“ im Kontrast zum Gespenst nicht allegorisches „Sprachrohr einer Weltauffassung“ (ebd., 407-408), sondern Ausdruck einer unheimlichen Begegnung mit sich selbst als fremdem Anderen wird (ebd.). 


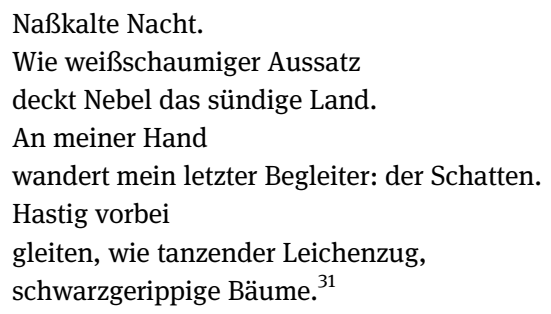

Der Doppelgänger und Begleiter als Schatten verwandelt zugleich den Einzug des Außen in einen poetischen Innenraum: Das Gespenst, so wie bei Schmitz, wohnt sich in den Körper ein. Der Leib wird zum verkörperten Schwerpunkt für diejenigen, die ihren Schwerpunkt verloren haben, und, wie es z. B. Tubutsch beschreibt, „Leute wie ich, deren Schwerpunkt außer ihrem Selbst liegt, irgendwo im Universum ... jedem Eindruck hingegeben wie Wachs ... die müssen ihr Sensorium unaufhörlich füttern [...].“32 Sie brauchen eine „Energiezufuhr“, wie sie das Gespenst bietet oder aber die Strahlenmagie okkulter Phänomene. ${ }^{33}$ Weitere Beispiele bieten Gustav Meyrinks Das grüne Gesicht (1916), ${ }^{34}$ Leo Perutz' Der Meister des jüngsten Tages (1923) ${ }^{35}$ oder Alexander Lernet-Holenias Ein Traum in $\operatorname{Rot}(1939){ }^{36}$

Der Doppelgänger und sein „Zwilling“, oder die Hülle und ihre Spiegelungen, verschmelzen zu einer neuen Einheit, wenngleich sie im Text als aufgefächerte Polarität existiert, oder wie Bubers Daniel bemerkt: „, $[\mathrm{A}] \mathrm{ch}$, tausend Masken hat das Unwirkliche.“37 Die Stadt der Gespenster tönt in den Synästhesien des Expressionismus als Farbe, Klang, Totentanz. Erst die Schatten können das Unwirkliche der Wirklichkeit überwinden und bilden eine neue Gemeinschaft als Dasein der Wesenlosen.

31 Oskar Kanehl: „Herbstnächtlicher Gang“, Aktion 4, H. 40/41 (1914), Sp. 809.

32 Ehrenstein, Tubutsch, 26.

33 Zur „Strahlenmagie“ als Zeitphänomen in seinen Differenzierungen siehe: Sabine Haupt, „Strahlenmagie. Texte des späten 19. und des frühen 20. Jahrhunderts zwischen Okkultismus und Science Fiction“, in: Gespenster. Erscheinungen, Medien, Theorien, hrsg. v. Moritz Baßler, Bettina Gruber u. Martina Wagner-Engelhaaf (Würzburg: Königshausen \& Neumann, 2005), 153-176, sowie im Kontext „utopischer Allianzen zwischen Physik und Metaphysik, Kunst und Technik“ siehe: Roland Innerhofer u. Rebecca Schönsee, „Einleitung“, in: Strahlen sehen - zu einer Ästhetik des Emanativen (Wien: new academic press, 2015), 7-21: 16.

34 Gustav Meyrink, Das grüne Gesicht [1916] (Leipzig: Kurt Wolff, 1917).

35 Leo Perutz, Der Meister des jüngsten Tages (München: A. Langen, 1923).

36 Alexander Lernet-Holenia, Ein Traum in Rot (Berlin: Fischer, 1939).

37 Buber, Daniel, 49. 


\section{Simon Kronberg. Biografische Impulse: Chassidismus - Tanz - Emigration}

Simon Kronberg, als Sohn jüdisch-galizischer Zuwanderer 1891 in Wien geboren, wächst mit den Traditionen eines chassidischen Judentums auf. Er beginnt früh ein unstetes Wanderleben, das ihn 1913 nach Hellerau zu Emile Jacques-Dalcroze führt, dessen Licht- und Bewegungschoreografien ihn nachhaltig prägen. ${ }^{38}$ Damit ist der Kontext spiritualistischer Reformbewegungen vorgegeben, wie sie Fidus oder die Tänzerin Loïe Fuller, ${ }^{39}$ aber auch Künstlervereinigungen und expressionistische Gruppierungen, etwa der Forte-Kreis, ${ }^{40}$ repräsentieren. Dazu gehören auch die Künstler rund um den Monte Verità mit ihrem „Traum vom Wahren, vom Einfachen, vom gottnahen Leben - der sozialen Utopie, der organischen Reform, der alternativen Existenz“41 innerhalb einer „sakralen Topographie“ ${ }^{\text {“42. }}$.

Aus Hellerau nimmt Kronberg ein auf das Leben bezogenes Konzept mit, das Performativität mit Individualität verbindet. Entsprechend rekurrieren seine Texte nicht auf eine theatrale, bühnengestützte Umsetzung, sondern zielen auf eine Inklusion des Alltäglichen und dessen Disharmonien wie Sinnlichkeitserfahrungen. Ebenso erfüllt sich das von ihm oft verwendete Motiv des Tanzes nicht in einer vollkommenen Entäußerung, sondern wird - wie das Bild des Schattens - rückgebunden an eine weltimmanente Erfahrung des Ich-Erlebens durch seine poetische Versprachlichung. Hellerau ist, wie Wolfgang Rothe betont, ein zentraler Ort für die Verschränkung von Leben und Tanz. ${ }^{43}$ Kronberg wird diese Verschränkung in seinen Texten, wie in seinem Wirken jenseits der Dichtung,

38 Zur Bedeutung des Tanzes bei Kronberg siehe Schönsee: „,Opfer, atemloser Wege, blind““. 39 „Die gespenstische Dimension dieses Tanzes, in dem die Bewegung nichts als ein vergeistigtes Entschwinden war, bestätigte nochmals, daß der Serpentinentanz im Grunde stets das Immaterielle beschwor“, s. Giovanni Lista, „Loïe Fuller oder die Macht des Geistes“, in: Okkultismus und Avantgarde. Von Munch bis Mondrian 1900-1915, hrsg. v. Schirn Kunsthalle (Frankfurt a. M.: edition tertium, 1995), 588-693: 590.

40 Weiterführend siehe Christine Holste, Der Forte-Kreis. 1910-1915. Rekonstruktion eines utopischen Versuchs (Stuttgart u. a.: M \& P, 1992), sowie Anna Wołkowicz, Mystiker der Revolution. Der utopische Diskurs um die Jahrhundertwende. Gustav Landauer - Frederik Van Eeden - Erich Gutkind - Florens Christian Rang - Georg Lukács - Ernst Bloch (Warszawa: WUW, 2007).

41 Wieland Schmied, „Harald Szeemanns Ausstellung ,Monte Verità‘ in Berlin. Artisten, Anarchisten und Vegetarier suchen die Wahrheit“, Die Zeit, Nr. 14, vom 30. März 1979.

42 Vgl. Harald Szeemann, Monte Verità. Berg der Wahrheit. Lokale Anthropologie als Beitrag zur Wiederentdeckung einer neuzeitlichen sakralen Topographie (Venezia-Martellago: Electa Editrice, 1978).

43 Vgl. Wolfgang Rothe, Tänzer und Täter. Gestalten des Expressionismus (Frankfurt a. M.: Vittorio Klostermann, 1979), 49 f. 
weiter ausarbeiten. Von Hellerau aus geht er 1914 nach Berlin und München; er studiert u. a. bei dem Schauspielerpaar Lindemann/Dumont in Düsseldorf und zieht schließlich nach Berlin. Bei Lindemann/Dumont lernt er die besondere Achtsamkeit im Hinblick auf Lautfolgen, die ihn sein Leben lang begleiten wird. Das Rheinland fungiert zu der Zeit als Transferregion und bietet wichtige Impulse: wie etwa die „Anarchisten Siedlung“ „Freie Erde“ oder die „Kölner Progressiven“, die aufgrund ihrer Verankerung in der Dada-Szene das Alphabet zum Programm erheben. Für das „international bekannte Reformtheater Dumonts arbeitete Gustav Landauer als Dramaturg“, 44 der ebenfalls für Kronberg wichtig werden wird. ${ }^{45}$ Kronberg verdient später seinen Lebensunterhalt als Phonetiklehrer und arbeitet sein Programm einer „rhythmischen Gymnastik der Sprache“46 aus: Laute, Buchstaben und Vokale werden innerhalb seiner Texte zu Kraftzentren, von denen die Bewegung als innerer Prozess der Selbstfindung in Verbindung mit einer textgesteuerten leiblichen Erfahrung ausgeht und ein individuelles Zielbewusstsein generiert. ${ }^{47}$ Hier gewinnt auch die gespenstische Dimension seiner Texte als „Reflexionsfigur der Medialität“48 an Bedeutung. Er adaptiert die Regeln der Dalcroze-Methode und formuliert verstärkt Gebete, ${ }^{49}$ um den Bereich der Kunst zu transzendieren, aber auch den Leser neu in das lyrische Geschehen einzubinden. So verbindet er in seinen Texten die Eckpfeiler seiner Biografie mit seiner Hinwendung zur Religion. Seine Texte, von denen nur wenige in der Aktion und der

44 Ausführlich hierzu: Gertrude Cepl-Kaufmann, „Yvan Goll. Eine Suche nach Zeitgenossenschaft“, in: Konjunktionen. Yvan Goll im Diskurs der Moderne, hrsg. v. Hermann Gätje u. Sikander Singh (Tübingen: Narr Francke Attempto, 2017), 9-29: 14.

45 Vgl. Wallas, Nachwort, 405.

46 Ebd., 363.

47 Die „Rhythmische Gymnastik“ von Émile Jacques-Dalcroze nimmt Anregungen aus der psychologischen Forschung der Zeit auf und wurde von dem Psychophysiker Wilhelm Wundt beeinflusst: „Wundt führte unter anderem die Entstehung von Zeitbewußtsein auf die Erfahrung des Rhythmischen zurück: nur dort, wo sich eine willentliche rhythmische Bewegung in der Natur erkennen läßt, kann auch ein Zeitbewußtsein entstehen“, s. Pia Witzmann: „,Dem Kosmos zu gehört der Tanzende“ - Der Einfluss des Okkulten auf den Tanz“, in: Okkultismus und Avantgarde. Von Munch bis Mondrian 1900-1915, hrsg. v. Schirn Kunsthalle (Frankfurt a. M.: edition tertium, 1995), 600-624: 604. Dieses Zeitkonzept lässt sich ebenfalls aus Kronbergs Texten ableiten.

48 Zur Figur des Gespenstes als „Reflexionsfigur der Medialität“ und Mittler zwischen Diesseits und Jenseits, um „Realität zu konstruieren“, vgl. Moritz Baßler/Bettina Gruber/Martina WagnerEngelhaaf, „Einleitung“, in: dies. (Hg.), Gespenster. Erscheinungen, Medien, Theorien, $12 \mathrm{f}$.

49 So betitelt und bezeichnet er seine Gedichte mit „Gebet“ (Kronberg, Werke I, 22, 203, 102), „Psalm“ (ebd., 47, 61, 62), „Kol nidre“, (ebd., 32, 64), „Kaddisch“ (ebd., 68, 14). Hier zeigen sich „Kronbergs Versuche ,einer Rekonstruktion des jüdischen Glaubens mit Hilfe einer die Brucherfahrung der Moderne verarbeitenden literarischen Verfahrensweise““, s. Armin A. Wallas, „Simon Kronberg“, in: Metzler Lexikon der deutsch-jüdischen Literatur, hrsg. v. Andreas B. Kilcher (Stuttgart/Weimar: Metzler, 2000), 351-353: 351. 
Dichtung veröffentlicht werden, ${ }^{50}$ integrieren insbesondere den Tanz als liturgisches Element. Als getanzter und „gezählter Schritt“51 bestimmt eine chorische Dimension das Maß der Dichtung und die Rhythmik der Bilder.

Nach dem Ersten Weltkrieg schließt sich Kronberg 1921 zionistischen Bewegungen an. Brotberufe wechseln neben seiner schriftstellerischen Tätigkeit parallel zu seinem Engagement in der Synagoge. In Berlin wird er Gruppenführer des Bundes Habonim Noar Chalzi Noar Haoved, ${ }^{52} 1934$ emigriert er nach Palästina. Doch auch dort geraten seine Texte in Vergessenheit. Er wird Chorleiter und arbeitet als Schuhmacher im Kibbuz Givat Chajim.

In seinem Engagement als Chorleiter drückt sich ebenfalls sein Selbstauftrag aus, die Wirkung des gesprochenen und gesungenen Wortes, genauer der Vokale, zu nutzen. Gesang nimmt er als „Selbstarbeit“ wahr. ${ }^{53}$ In einer Durchwirkung von Leben, Text, Gesang und Gemeinschaft wird der Buchstabe bzw. der Vokal als Kraftzentrum positioniert. Seine Ehrfurcht vor dem Schreiben als kulturtechnischem Vorgang verbindet sich mit einer kosmologischen Komponente: Das Wort wird zum Mittler und Wegweiser zwischen einer religiös angebundenen Existenz und dem profanen Leben. Seine rhythmischen Texte überführen in eine surreale Welt. Damit wird bei Kronberg der Zusammenhang von Schreiben und Leben als Kulturtechnik essenziell.

Gerade im Sprachexperiment, angeregt durch seine Erfahrungen in Hellerau, in seiner Auseinandersetzung mit Schauspielkunst und performativem Sprechen sowie dem Chorsingen wird die Lichtmetaphorik zur Quelle eines Erlösungsgedankens, nämlich einer Befreiung aus einer schattenhaften, weil verachteten Existenz. Es geht Kronberg, wie ich im Folgenden zeigen werde, nicht so sehr um eine apokalyptische Beschwörung, die einen eschatologischen

50 Zur Publikationslage siehe insbesondere den Eintrag zu Simon Kronberg in: Lexikon deutschjüdischer Autoren, hrsg. v. Renate Heuer, Bd. 14, unter Mitarbeit v. Andrea Boelke-Fabian, Rainer Brändle, Abdelhaq El Masmoudi u. a. (München: KG Sauer 2006), 364-369.

51 Z. B.: „Bleib stehen, Chamlam! Zähle deine Schritte erst, bevor du grundlos eine Nacht umgehst. Binde deine Schritte mit dem Denken, wenn sie fallen wollen“ (Kronberg, „Chamlam“, 154). „Leid legt Schritt zu Schritt, in sich gemessen, in sich den Sinn. Doch wir begegnen dem Leid. Wir messen ihm zu“ (Simon Kronberg, Schimen in der Stille, in: ders., Werke II, 9-26: 25). Zu dieser Thematik siehe ebenfalls: Hoffmann, Religiöse Turbulenzen, $135 \mathrm{f}$. Hoffmann weist darauf hin, dass mit den Worten „So zählte er“ ein Gebet des Jom-Kippur-Gottesdienstes beginnt, ,,das während der liturgischen Rekapitulation der Opferung im Tempel gesprochen wird. Es bildet den rituellen Vorgang der Blutbesprengung an der Heiligen Lade ab“ (ebd.).

52 Vgl. ausführlich Wallas, Nachwort, 399.

53 Ebd., 404. 
Heilsgedanken nach sich zieht, ${ }^{54}$ sondern um eine Frage nach Identität und Existenz in einer Erfahrung des Ausgeschlossenseins. Kronbergs utopische Visionen suchen eine leibliche Anbindung und verbinden diese nicht selten mit der gespenstischen Gestaltwerdung transzendenter Bilder. Diese werden über expressionistische Komponenten wie den Laut, den Schrei evoziert. Singen und Tanzen werden ebenso wie die Schatten und Gespenster Teil eines pluralistischen Ansatzes, in dem der Wechselgesang zum zentralen Bestandteil einer kabbalistischen Lebensdurchdringung wird, die Übergänge schafft, integrativ und identitätsstiftend wirkt.

Simon Kronberg stirbt 1947 als kaum gelesener oder aufgeführter Autor. ${ }^{55}$

\title{
4 Kunstform, Dichtung und Selbstportrait: Kronbergs Schattenwürfe
}

Seine biografischen Erfahrungen beeinflussen nicht nur seine Lyrik, sondern insbesondere seine Erzählungen. Bereits Karl Otten erkennt in seiner Narrenfigur Chamlam ein Selbstporträt.

\begin{abstract}
Chamlam ist vielleicht das Vollendetste, was der existentiell gerichtete Expressionismus hinterlassen hat. In seiner bildhaften, den schöpferischen Prozeß Wort für Wort darbietenden Selbstanalyse bricht manchmal die Verzweiflung an Gott durch das jüdische Gefäß und zerbricht es fast. Die Selbstdarstellung treibt Simon Kronberg zum Theater, aber es ist ein fernes Theater der Ekstase, dichterisch-unwirklicher Handlung, das er gestaltet. ${ }^{56}$
\end{abstract}

Kronbergs Schattenfiguren entfliehen dem Raster der Stadt und ihren Gittern. So formiert sich um seine Narrengestalt auch eine Geistererzählung. Der Narr entflieht nicht nur dem Schattenhaften, sondern trägt zugleich die Gespenster seiner Wirklichkeit mit sich. Das ihm Bekannte, Heimliche wird unheimlich im Sinne Freuds. ${ }^{57}$ Der Abwehreffekt wird jedoch mit lyrischen Mitteln überwunden. Der Text beschwört spiritistisch liminale Orte, die Schatten. Zugleich bietet er dem

54 Vgl. Klaus Vondung, The Apocalypse in Germany (Columbia, Mo.: University of Missouri, 2000) 142 u. 372. Kronberg entfernt sich von einem expressionistisch-apokalyptischen Erzählen, wenngleich er auch solche Elemente in seine Texte integriert, insbesondere am Beispiel des Simson-Mythos.

55 Zur ausführlichen Biografie siehe die Zeittafel in: Kronberg, Werke II, 325-334, siehe ebenfalls Wallas, „Simon Kronberg“, in: Metzler Lexikon der deutsch-jüdischen Literatur, 353.

56 Karl Otten, Das leere Haus, Prosa jüdischer Dichter (Stuttgart: Cotta, 1959), 645.

57 Sigmund Freud, „Das Unheimliche“, in: Sigmund Freud. Studienausgabe in zehn Bänden mit einem Ergänzungsband, hrsg. v. Alexander Mitscherlich, Angela Richards u. James Strachey, Bd. 4: Psychologische Schriften (Frankfurt a. M.: S. Fischer, 1994), 243-274: 244. 
heimatlos gewordenen Ich an, in ein Licht-Gewand als neue tragende Hülle zu entfliehen. So vereint die Erzählung „Chamlam“ ein religiöses Element mit einer performativen Metaphorik. ${ }^{58}$

Der Rezipient wird hineingezogen in einen Klang- und Farbraum, der vor allem über wechselnde Personalpronomina bewegt wird. Es eröffnet sich in diesem spektralen Auflösungsmoment sprachlich eine Parallele zu den Reformtänzen aus Hellerau, die Kronberg einst studierte, aber auch zur performativen Kunst von Loïe Fuller oder Mary Wigman, die ebenfalls bei Dalcroze studierte. Zugleich findet sich in der existenziellen Radikalität seines Anspruchs auch ein Alleinstellungsmerkmal.

Simon Kronberg verbindet seinen Doppelgänger und Schatten mit Lichtvisionen, die seine Lyrik wie Prosa grundlegend prägen. Kennzeichnend für Kronbergs Texte ist dabei die Aufweichung der Gattungsgrenzen. Lyrik und Prosa verschränken sich. Seine Prosa verbindet immer wieder rhythmische Versmaße und liturgische Elemente, ${ }^{59}$ seine Lyrik öffnet sich der ungebundenen Rede. So ist etwa sein Prosagedicht „Chamlam erzählt sich Märchen“60 (1916) eine Vorstufe zu seiner späteren Erzählung „Chamlam“ (1921). Das Gedicht ufert ins surreal Phantastische aus, wandelt sich zur grotesken Erzählung. Kronberg selbst erklärt: „[D]enn ich kenne keine Umgrenzung des Gedichtes. “61 Entsprechend gibt er in der Erzählung „Chamlam“ die Rolle des Erzählers auf, ${ }^{62}$ die Erzählstimme wird intermedial gespenstisch und die Figur schattenhaft. Aufgrund der Durchlässigkeit der Gattungen bietet sich ein direkter Vergleich zwischen Lyrik und Prosa an. Die Lichtmetaphorik von Kronbergs Lyrik schärft die Bildsprache seiner grotesken Erzählungen; beide stehen in Wechselwirkung. Seine letzte Schaffensphase, die geprägt ist von seinem dramatischen Werk, lässt sich schließlich als Auflösung der Spannung zwischen Lyrik und Prosa lesen. ${ }^{63}$

58 Auch in seiner Lyrik liegt das performative Element in der Verschränkung von Rhythmik, Bildsprache und Zahlenmystik.

59 Insbesondere die Totenklage (vgl. Wallas, Nachwort S. 280). Zur Bedeutung des Liturgischen bei Kronberg siehe insbesondere Hoffmann, Religiöse Turbulenzen, 61-62, 113-138.

60 Simon Kronberg, „Chamlam erzählt sich Märchen“, Aktion 6 (1916) H. 51/52 (= Sonderheft „Friede auf Erden“), Sp. 695 f., erschienen am 23. Dezember 1916 (=ders., Werke I, 10 f.).

61 Tagebuchaufzeichnung Weihnachten 1919, zit. n. Wallas, Nachwort, S. 386.

62 Ebd.

63 Eine ausführliche Analyse seiner dramatischen Texte bietet Armin A. Wallas, „Kibbuznik, Schuhmacher, Gesangslehrer und Dichter. Simon Kronberg in Palästina (1934-1947)“, Exil 15 (1995), 36-68; http://buecher.hagalil.com/sonstiges/kronberg.htm [23.02.2020]. 


\section{Atem, Leib und leuchtende Verheißung. Kronbergs expressionistischer Messianismus}

Kronbergs Protagonisten sind Suchende. Sie sind durchlässige Schemen, die im Leid ihr Ich neu zu erobern suchen: Gemeinsam suchen sie einen Geist, bei Kronberg den „Wind“, das „Wanderwort“, ${ }^{64}$ der das Gespenstische ihrer Welt, welches die Härte der Biografie Kronbergs und seiner Zeitgenossen oft verbirgt, in eine neue Gemeinschaft aufnimmt. Es geht ihm um eine pneumatische Durchdringung dieser Lebenswelten, für die Wind und Schatten als Verdoppelung von Atem und Leib repräsentativ werden. Das Flüchtige gesellt sich dem Beständigen, wie der eigenen Schrittlänge, zu. Darin unterscheidet er sich von Autoren wie Albert Ehrenstein, Franz Werfel, Oscar Schmitz oder Carl Ehrenstein. ${ }^{65}$

Der in seinem 1923 in der Literaturzeitschrift Die Dichtung erschienenen InselGedicht beispielhaft dargestellte Zusammenhalt besteht aus einem „neuen Atem im Leid“, der Kronbergs Utopia, seine Insel, umweht:

Schritt und Genügen sind und ein neuer Atem im Leid.

Genügen ist Lächeln mit einem Schatten Seligkeit. ${ }^{66}$

Aus dem Zerbrechen des Leibes im Licht erwachen die Schreitenden zum Traum, wie es das lyrische Ich in dem Gedicht Die Insel erlebt. Der „Schattenvolle“ nimmt seinen „Atem von der Insel“, 67 tritt als „Schattenwurf“ zwischen den Wechsel von Tag und Nacht in eine Zeit des Traums. Kronberg porträtiert einen Schattentänzer, der im Tanz in eine neue Zeit hinüberführt, weil er das gespenstische Element mit seinem Leben konfrontiert und sich mit ihm in einen produktiven (Traum-)Dialog setzt. Es ist eine a-temporale Welt des Traums, der ihn aus dem Exil erlöst - hier wird seine Dichtung surreal. Kronberg beschreibt dies ebenfalls in dem Gedicht „Tag - Nacht“ (1919). ${ }^{68}$ Kronbergs Schattenfiguren folgen einer „leuchtenden

64 Vgl. u. a. Simon Kronberg, „Der Jude“, in: Die Dichtung, Zweite Folge, Zweites Buch, 1923, 80 (=ders., Werke I, 27).

65 Das pneumatische Element ist nicht Zeichen der Vergänglichkeit, wie z. B. in dem gleichnamigen Gedicht von Carl Ehrenstein, das fragt: „In hundert jahr, was weiß der wind davon?“, s. Carl Ehrenstein, „Vergänglichkeit“, Prager Presse (30. Oktober 1921), Sonntags-Beilage 12, zit. in: Wallas, Expressionismus 85.

66 Simon Kronberg, „Die Insel“, in: Die Dichtung, Zweite Folge, Zweites Buch, 1923, 77 (=ders., Werke I, 24).

67 Ebd.

68 Simon Kronberg, „Tag - Nacht“, in: ders., Werke I, 82 (zu Lebzeiten unveröffentlicht, 29.12. 1919), vgl. auch: „Zwischen den Lichtern traten wir Schatten“ („Liebe“, in: Werke I, 86 [zu Lebzeiten unveröffentlicht, Sept. 1925]). 
Verheißung“. Es ist ein Leuchten, das Blendungsphantasmen erzeugt und in einer inneren Einkehr seine neue Ruhe und Kraft findet: Nacht erscheint als Lichtbrechung und „farbiger Sinn“ der Nähe. ${ }^{69}$ Kronbergs Gespenster und Schattenwürfe, so meine These, sind der Versuch, aus dem ontologischen Nichts zurückzuführen in ein absolutes Sein als „Licht“ in einer mystischen Konfiguration des Glanzes ${ }^{70}$ im Zeichen eines expressionistischen Messianismus. ${ }^{71}$

\section{[...]. Ich überhäufe Stunden}

mit dem Atem eines Wartenden.

Gemach! Das Licht schlitzt müde Schultern, und ich sinke Abend schon am Tag.

Tag fällt, farbig sehe ich den Sinn

der nahen Nacht. Ich bin zum Traum erwacht. ${ }^{72}$

Der Traum Kronbergs mündet in einem kabbalistisch-zionistischen Bestreben als Suche nach dem Neuen Jerusalem.

Nicht nur wegen seiner Ausgrenzungserfahrung wird Kronberg zum „geradezu paradigmatischen Dichter des jüdischen Schicksals“, wie Wallas bemerkt. ${ }^{73}$ Sein „existentielles Bewusstsein von der Schuldhaftigkeit des Lebens teilt Kronberg mit anderen Autoren seiner Generation, etwa mit Georg Trakl, Franz Kafka und Franz Werfel“. ${ }^{74}$ Er gestaltet dabei auf spezifische Weise Gegen-Welten, die teils ins Surreale, weniger ins Phantastische gleiten.

\section{Simon Kronbergs Schatten als tragende Hülle einer Sprache der Stille}

So zeigt etwa das Gedicht „Mich mauert die Stille“ (1915) ${ }^{75}$ eine starke Entgegensetzung von Licht und Schatten am selben Ort der Stadt: Stille wird hier zum Modus

69 Kronberg, „Tag - Nacht“, 82.

70 Glanz= splendor in der scholastischen Tradition. Alttest. kabod, griechisch doxa, lateinisch gloria.

71 Vgl. hierzu Lisa Marie Andersons ausführliche Analyse: German „Expressionism“ and the Messianism of a Generation (Rodopi: Amsterdam, New York 2011), 11.

72 Kronberg, „Tag - Nacht“, 82.

73 Wallas, Nachwort Expressionismus, 282.

74 Ebd., 284.

75 Simon Kronberg: [Mich mauert die Stille], in: ders., Werke I, 41 (zu Lebzeiten unveröffentlicht, Okt. 1915). 
der Abgrenzung und zum erlösenden Weg aus einer angsterregenden, abweisenden Umgebung hin zu den ihr zugleich inhärenten utopischen Anteilen. Eine Stadt der Toten steht einer Stadt der Lichter gegenüber und verbindet sich mit ihnen. Die Toten werden damit zu Wesen des Glanzes. Das lyrische Ich dazwischen „mauert sich in Stille“ ein und grenzt sich so ab; setzt sich in Opposition zu einer zusehends anthropomorph wahrgenommen Welt der Ding-Symbole und Phänomene:

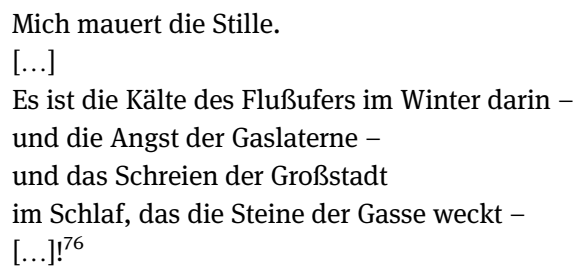

Das expressionistische Bild des von der Welt ausgesperrten Dichters ${ }^{77}$ wird leicht abgewandelt. Das im Gedicht beschriebene Gefängnis klammert den Außenraum nicht aus, um ihn aus einer neu gefunden Energie heraus zu zerstören, sondern nimmt ihn vielmehr auf und wandelt ihn um. Die „schreiende“ Stille weckt nicht nur die „Steine der Gasse“, sondern vor allem den lebendig Toten, das lyrische Ich, zu einem Sphärenklang des Wachsens, der sich im Rauschen der Natur ankündigt. Der lebendig Tote hört sich im

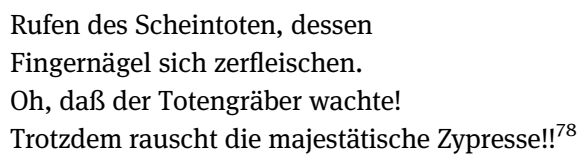

Der „Ruf“ der Scheintoten mischt sich mit dem Rauschen der Umwelt - gemeinsam führen diese Bilder zu einer eigenen Form lautlicher Bewegtheit, die sich zum performativen Akt steigert. Sein Sprechakt wird zur Sprechkunst. ${ }^{79}$ Es entwickelt sich eine Art Frage-Antwort-Spiel zwischen gespenstischem und leiblichem Sprechen, das sich im Raum realisiert.

76 Ebd.

77 Siehe hierzu ausführlich: Rothe, Tänzer und Täter, 11-21. Beispielhaft sind nach Rothe DichterNarren, die ihre Defizienz ins Positive verkehren und als „Waffe“ gegen eine bürgerliche Welt der Spießer nutzen (vgl. ebd., 11). Kronberg dagegen nutzt eher die Figur, um auf einen Weg zu einem utopischen Gegenort hinzuweisen, der sich als Gegenklang im Dichter erfüllt.

78 Kronberg: [Mich mauert die Stille], in: ders., Werke I, 41.

79 Vgl. Wallas, Nachwort, 362. 


\section{Seelenführerin und Weisheit: Imaginationen des Weiblichen}

Dem gespenstischen Erschrecken, der Angst, stellt Kronberg immer wieder eine namenlose, mystische Frauenfigur zur Seite, als Richterin über das Elend seiner Welt und Allegorie der Weisheit. ${ }^{80}$ Ihre Aura bedeutet ihm die „leuchtende Verheißung "81 einer in Stille klingenden Welt.

In einer Verkehrung der traditionellen Gespenstersymbolik, in der das Gespenst als Manifestation des Irrealen und Einbruch des Unheimlichen in die Welt des Diesseits tritt, ${ }^{82}$ besänftigt Kronbergs Figur „der Frau“ als Herrin über die Stille und Künderin einer lautlosen Sprache der Schatten nun umgekehrt das angsterregende und unheimlich erscheinende Diesseits. „Die Frau“ als Herrin führt zu einer Form der Versöhnung der in Polaritäten zerfallenden Welt. So wandelt sie sich zur Allegorie der Weisheit als Medium der Welterkenntnis.

Kronbergs allegorische Figur „der Frau“ ist weder eine Todesbotin, wie etwa in Werfels „Gerichtstag“ (1919) ${ }^{83}$ die „Mittagsgöttin“, die nach der „Geburt der Schatten“ dem Gaukler als „mütterlicher Tod“84 erscheint, noch eine subversive Verführerin und mädchenhafte Muse, wie etwa in Thomas Manns Gespenstererzählung „Der Kleiderschrank“ (1899). ${ }^{85}$ Sie ist auch keine kalte Botin der Maschinen wie Döblins Tänzerin. Vielmehr ist sie eine weise Mentorin und Seelenführerin auf der Suche des Individuums nach seiner (irdischen) „Verwirklichung“, wie sie Martin Buber in seinem oben zitierten Daniel-Gespräch beschreibt. Für Kronberg offenbart sich diese Verwirklichung in einer mystischen Liebeserfahrung, die zugleich als Wiedergeburt erlebt wird. Seine Suche nach Geborgenheit $^{86}$ folgt einem Gesetz der Laute, das sich in ein synästhetisches Tönen

80 Neben „Chamlam“ in seinen dramatischen Texten z. B. Schimen in der Stille; in: ders., Werke II, 9-26; Die Wand, in: ebd., 94-98, aber auch in seiner frühen Lyrik, z. B. zwei Gedichte unter dem Titel „Frau“, in: Werke I, 33 u. 34 (zu Lebzeiten unveröffentlicht, beide Juli 1915).

81 Kronberg, „Chamlam“, in: ders., Werke I, 133-179: 178.

82 Vgl. Wilpert, Gespenstergeschichte, 360.

83 Franz Werfel, Der Gerichtstag, in fünf Büchern (Leipzig: Kurt Wolff, 1919).

84 Franz Werfel, „Die Mittagsgöttin. Zauberspiel“, in: ders., Der Gerichtstag, 166-238: 231. Laurentin, der Protagonist, wünscht sich nach der Begegnung mit der Mittagsgöttin am Ende des „Zauberspiels“: „Ich will dem gespenstischen Gespenst begegnen: mir selbst“ (232) - das Zauberspiel führt in den „Gerichtstag“, das fünfte Buch, über die am Ende stehende „Geburt des Lichts“, ist zugleich ein „Traum, der zur Verwesung strebt“ (299), Buch I trägt den Titel Geburt der Schatten (9-20), https://archive.org/details/3322807/mode/2up [27.10.2010].

85 Thomas Mann, „Der Kleiderschrank - eine Geschichte voller Rätsel“, Neue Deutsche Rundschau 10, H. 6 (1899), 660-665.

86 Vgl. Kronberg, „Chamlam“, 159. 
auflöst, wobei die Synästhesie nicht selten zwischen Geste (Lächeln), Licht und Laut gegeben ist.

\section{Chamlam, Schlemihl-Figur und heiliger Narr}

Kronbergs Texte variieren immer neue Schattenfiguren: So bindet er ein fiktionales Ich in die Texte ein, als ,verlorenen Sohn" ${ }^{\text {“87 }}$, vor allem aber als Schlemihl-Figur. ${ }^{88}$ Sein in diesem Zusammenhang wichtigster Text ist die 1921 erschienene Erzählung „Chamlam“. Chamlam, was auf Hebräisch so viel wie Dummkopf bedeutet, ist eine Schlemihlfigur, ${ }^{89}$ die jedoch anders als bei Chamisso nicht ins Exil einer Natureinsamkeit führt, sondern sich eine Welt der Schatten durch Farb- und Lichtspiele neu erobert. ${ }^{90}$ Sie begleitet Kronberg bereits seit 1916 in Gedichten. ${ }^{91}$ Chamlam, der tanzende Narr, ist ein Schattensucher, ${ }^{92}$ der aus seinem Welt-Gefängnis auszubrechen versucht.

Auf seinem Weg der Initiation in eine neue Welt des Lichts durchwandert Chamlam mehrere Phasen, die im Folgenden entwickelt werden sollen. „Das Leben blättert“"93 von ihm ab. Im Bewusstsein, seine Hülle verloren zu haben, sucht er ein neues Kleid, sein „Licht-Kleid“. Chamlam fühlt sich beständig in einem Kampf gegen die anderen der „billigen Begierde“, ${ }^{94}$ die im Tretrad der Zeit gefangen sind. „Sie wollen bestrafen, weil man sie aufhielt. Sie sind einig. Sie fangen an zu laufen. Sie atmen, eine Wand der billigen Begierde gegen einen Einzelnen. [...] Der einzelne Chamlam starrt durch das Gitter, ein zitternd Einzelner."95 Dieses Gefühl des Ausschlusses wird nur partiell zur Begegnung mit Schreckgestalten. Es führt in erster Linie zur Einführung einer Erlösungsgestalt: Chamlams Seelenführerin ist in Übereinstimmung mit Kronbergs Figuren idealisierter Weiblichkeit eine spektral-göttliche und namenlose Frau, die dem heiligen Narren als Grenzgänger zwischen den Welten, als Richterin und Allegorie der Weisheit zur Seite steht. Ihr Licht

87 Siehe auch die gleichnamige Erzählung, in: ders., Werke I, 325-329, sowie Kommentar Werke I, 387.

88 Vgl. ausführlich Wallas, Nachwort, 380.

89 Ebd.

90 Adelbert v. Chamisso, „Peter Schlemihls wundersame Geschichte“ [1814], in: ders., Sämtliche Werke, Bd. 1, hrsg. v. Jost Perfahl (München: Winkler, 1975), 13-66.

91 Siehe Kronberg „Chamlam erzählt sich Märchen“, 10-11.

92 Vgl. Kronberg, „Chamlam“, 176.

93 Ebd., 141.

94 Ebd., 142.

95 Ebd. 
reflektiert die „leuchtende Verheißung“96 einer in Stille klingenden Welt der Geborgenheit.

Kronberg strebt eine Durchdringung und Überwindung der Grenzen an, um eine Transformation und Transgression der von ihm erlebten „Gitterstruktur“ des Lebens in der Stadt zu erreichen. Damit unterbricht er auch die Tradition der Schlemihlgeschichte, genauso wie den Diskurs expressionistischer Gespenster, die als „Umbrae Vita“97 und dämonische Spukgestalten die „zerstörerischen Kräfte von Krieg, Krankheit und Tod“ repräsentieren. ${ }^{98}$ Chamlam ist ein „Schattensucher“, weil er ein utopisches Potenzial sucht, das ihm Schutz bietet und ihm einen Weg zu einem aktiven Erleben seiner Sinnlichkeit bietet. Hier zeigt sich Kronbergs Alleinstellungsmerkmal des Schattens: Ihm geht es nicht um die Kritik an einem „schattenhaften“ Menschen, wie sie für den Expressionismus beispielhaft ist. Kronberg nutzt das Bild des Schattens vielmehr als Suche nach einem Obdach und einer positiv besetzten Anima-Figur als Liebes- und Lichtgestalt und als Medium zur emphatischen Verbindung mit seiner Umgebung. Damit hat er eine Sonderstellung gegenüber den Dichtungen etwa Georg Trakls: In seinem Gedicht „Der Schatten“ wird die Begegnung mit seiner Anima zu einer schreckhaften Gespenstererfahrung: Der Schatten spiegelt das triebhafte Selbst. Das lyrische Ich sieht den Schatten. „Gewaltig verzerrt, ein wunderlich Tier, /Das lag wie ein böser Traum vor mir.“99 Georg Heyms bedrückende Schattengedichte, die um die „Hora Mortis“"100 kreisen, weisen ganz wie Albert Ehrensteins Tubutsch auf die Leblosigkeit der Städtebewohner und deren schlafwandlerische Hoffnungslosigkeit.

\section{Neue Wege und intersubjektive Raumspiele}

Dieser Hoffnungslosigkeit begegnet Kronberg mit einer Neuausrichtung seiner Figuren im Raum. Im Gitter der Stadtfenster gefangen, fühlt Chamlam sich zwar als

96 Ebd., 178.

97 Georg Heym, Umbrae Vitae. Nachgelassene Gedichte, hrsg. v. David Baumgardt, Golo Gangi [d. i. Erwin Loewenson], Wilhelm S. Guttmann, Jakob von Hoddis und Robert Jentzsch (Leipzig: Rowohlt, 1912).

98 Wilpert, Gespenstergeschichte, 412; von Wilpert zeigt dies am Beispiel von Georg Heyms Das Schiff, in: ders., Dichtungen und Schriften, Bd. 2: Prosa und Dramen, hrsg. v. Karl Ludwig Schneider, m. Carl Schmigelski (Hamburg/München: Heinrich Ellermann wbg, 1962), 52-65.

99 Georg Trakl, „Der Schatten“, in: ders., Dichtungen und Briefe (aus dem Nachlass 1909-1912), hrsg. v. Walter Killy u. Hans Szklenar (Salzburg: Otto Müller, 1969), 266, Z. 5-6.

100 Georg Heym, „Hora Mortis“, in: ders., Dichtungen und Schriften, Bd. 1: Lyrik (Hamburg/ München: Verlag Heinrich Ellermann, 1964), 317-318, 320-321: 320. 
der Einsame in der Masse der Städter. Anders als in den Erzählungen von Döblin oder Schmitz gewinnt das „Andere“ jedoch zu keiner Zeit Gewalt über den Narren. Es ist vielmehr der andere (heilige) Weg. Der wiederholt von diesem Anderen geschlagene Chamlam bleibt einzeln. Er ist ein Beobachter, der seinen Weg zwischen den Zeiten geht. ${ }^{101}$ Mit seinen wiederholten Verweisen auf die temporale Ebene einer geweiteten Zeit ${ }^{102}$ geht eine Neustiftung seiner Identität einher. Zwischen den Zeiten zu gehen, heißt eben auch, sich des gerichteten Zeitstrahls von Geburt, Leben, Tod zu entheben. Auch von hier aus erklärt sich seine Integration spiritueller Metaphorik: Sie eröffnet eine Zeit jenseits der Zeitzählung - „die Stunde schwebt von mir“103 - und ermöglicht eine davon losgelöste, räumliche Identitätsbildung.

So erschließt sich in den Schwebungen seiner Identität ein eigener Raum aus Multifokalität: Die Elevationsbewegungen wie die des Blühens ${ }^{104}$ und Wachsens ${ }^{105}$ werden in ein intersubjektives Spiel rückgekoppelt, das den starren Bezugsrahmen einer rational gesteuerten Welt erschüttert. Das Raumgefüge gerät ins Wanken. Das Erzähl-Ich wechselt beständig, und nicht immer ist klar, ob Chamlam oder sein Doppelgänger und Freund gerade spricht. ${ }^{106}$ Er fragt: „Bin ich denn ein Toter, dem man alle Welt in Bretter sperrt?“"107 In der Frageform öffnet sich eine Möglichkeit der Verwandlung. Im Sprechen können die absperrenden Bretter zerbrechen, kann der „lebendig Tote“ in ein anderes Leben der Wandlungen entkommen: Die Spaltung von Ich und Gespenst schlägt nicht in eine lebendig-tote Zombiefigur um, sondern führt aus der Doppelung in eine Erlösung als mystische Entgrenzung des Selbst.

Damit fügt Kronberg Chamlam in den Gespensterdiskurs der Moderne ein: „Gespenster können sowohl die innere Vielschichtigkeit des Subjekts als auch die verwirrende Uneindeutigkeit der Welt und Vieldimensionalität der Sprache in ihrer doppelten Ausprägung als langue und parole verbildlichen."108 Kronbergs Figurenspiel wird jedoch gerade nicht zur „Chiffre für die Entmächtigung und

101 Vgl. Kronberg, „Chamlam“, 134, 141.

102 „Tag oder Nacht - ich bemerke, daß die Stunde, eine Seifenblase erschienen ist. [...] Ich kann die Stunde nicht begrüßen, ich diene ihr“ (ebd., 172).

103 Ebd.

104 Vgl. Rothe, Tänzer und Täter, 80.

105 Vgl. ebd., $60 \mathrm{f}$.

106 Damit steht er in klarem Gegensatz zu einem Expressionismus, dem es vor allem um die „Überflutung der Welt durch das Ich geht“, wie z. B. Paul Hatvani: „Im Expressionismus überflutet das Ich die Welt“, s. Paul Hatvani [d. i. Paul Hirsch], „Versuch über den Expressionismus [1917]“, in: Texte des Expressionismus. Beitrag jüdischer Autoren zur österreichischen Avantgarde, hrsg. v. Armin A. Wallas (Wien: Edition Neue Texte, 1988), 9-12: 9.

107 Kronberg, „Chamlam“, 165.

108 Baßler/Gruber/Wagner-Engelhaaf, „Einleitung“, 18. 
Selbstentfremdung des Ichs“109, sondern vielmehr zum Moment der Selbstfindung als Konnex zu einer „ultimativen Wirklichkeit“, ${ }^{110}$ die im Sinne Bubers als weltimmanente „Verwirklichung“ verstanden werden kann. Seine „neue Koordination der Sinne“111 gestaltet Kronberg als zwischenmenschliche Vibration. Anders als im expressionistischen Wahrnehmungsparadigma, das im Strahlen den Materialismus der Körper aufhebt, ${ }^{112}$ werden Vibration und Strahlen hier zur Basis einer neuen Beziehung zu sich selbst.

\section{Kronbergs „Große Mutter“: Die Frau als Erlöserin und Klangmysterium}

Chamlam begegnet auf seinem Weg wiederholt einer Frau, die symbolisch Mutter und Geliebte ist. Der „Muttersucher unter den Gojims“113 sucht eigentlich ein Gesetz der Liebe: „Ich will auf dieser Welt mir ein Gesetz ergründen, das die Liebe schützt und sie nicht gallig macht. " ${ }^{114}$ Hüterin dieses Gesetzes ist in Kronbergs Erzählung eine Anima-Figur und „Große Mutter“, der er mehrere Gesichter gibt. Dieses Motiv wird er besonders in seiner späten Dramatik wiederholen und ausführen. ${ }^{115}$ „Die Frau“ als Erlöserin zeigt sich Chamlam in Gestalt der

109 Monika Schmitz-Emans, „Gespenstische Rede“, in: Baßler/Gruber/Wagner-Engelhaaf (Hg.), Gespenster. Erscheinungen, Medien, Theorien, 229-52: 242.

110 „Poetic expression is not couched in language that talks ,about' the transcendent; rather it takes the reader immediately to the essence of the divine, and thereby serves as a catalyst for an experience that extends beyond anything language can portray, evoking at once the silence beyond our limited reality and the joyous fullness of the world connecting to Ultimate Reality“, s. David W. Atkinson, „Fullness and Silence - Poetry and the Sacred Word“, in: Silence, the Word and the Sacred [1989], hrsg. v. E. D. Blodgett u. H. G. Coward (Waterloo, Canada: Wilfrid Laurier UP, 2006), 189-204: 200.

111 Hierzu ausführlich: Christoph Asendorf, „Neue Koordination der Sinne“, in: ders., Ströme und Strahlen. Das langsame Verschwinden der Materie um 1900 (Berlin: anabas, 1989), 122-124.

112 Siehe Asendorf, Ströme und Strahlen, 148.

113 Simon Kronberg, [Es war ein tiefes Versinken in Fremdheit] (zu Lebzeiten unveröffentlicht, 1920), in: ders., Werke I, 82; ebenso ders., „Chamlam“, 139.

114 Kronberg, „Chamlam“, 155.

115 Vgl. Wallas' Anmerkungen zu Schimen in der Stille (Kronberg, Werke II, 9-26), Nachwort, 282, und zu Ehud. Ein Richter in Israel (Werke II, 130-163; Kommentar: Werke II, 310). 
Schechina. ${ }^{116}$ Allegorisch ist sie zugleich als die große Richterin gestaltet, und man mag Hinweise zu seiner späteren „Deborah-Figur“117 in Anlehnung an die Prophetin und „Mutter in Israel“"118 erkennen: „Die Dame hat hohe Augen wie ein Richter, der mir nur Gnade noch erweisen kann." ${ }^{119}$ Als göttliches Wesen öffnet sie den Klangraum für den horchenden Chamlam: „Atemlos horche ich und trete aus dir heraus und sehe, wie dein Vater dir entgegenkommt. "120 Sie erfüllt Chamlams Sehnsucht nach „einer aushorchenden Liebe“ ${ }^{\text {“121 }}$, die ihm seine Lebendigkeit extrahiert und neu vor Sinnen führt. Im Hinblick auf die Thematik einer Geschlechtlichkeit nach dem Zersplittern des Körpers bzw. dem Gespenst als Geschlecht ohne Körper zeigt sich hier, wie Kronberg die Vision seiner idealen Dame dem Körper seiner Mutter entzieht: Sie tritt aus ihm heraus und wandelt sich zu einem göttlichen Geschlecht, das lediglich anwesende Stimme ist. Ihr Klang wird schließlich zu einer „,aushorchenden Liebe“, wodurch die geschlechtliche Bindung ihre mystische Auflösung erlebt.

Chamlam ermöglicht dies eine Rückführung in seine Kindheit, die sich mit Kronbergs Biografie kreuzt. Er fragt: „Warum zerriß die Mutter mir mein Leben? Warum war so viel Fluch an ihrer Schürze?“122 Chamlams Weg kann entsprechend autobiografisch als Flucht Kronbergs angesichts seiner eigenen negativen Kindheitserfahrung gedeutet werden. Chamlam empfindet sich als „Ziel der Zertrümmerung aufgebauter Jahre“. ${ }^{123}$

Ich fürchte mich vor mir, denn ich gehe allein nach Hause. Die Freude meines Tages liegt erstochen. Ich soll die Dinge gelten lassen, wie sie mich, ganz tot, besehen. Ich lache aus verschiedenen Ohnmachten heraus und beschwöre mich, am Leben zu bleiben. Ich gehorche mir. - Ein geschlossenes Haustor ist jetzt eine Wand voll Gelächter. ${ }^{124}$

Wie Hohn scheint das Gelächter auf Chamlam niederzustürzen, und die Erzählerstimme bestätigt das. Tatsächlich ist es nur ein Tribunal innerhalb einer

116 Diese imaginierte Weiblichkeit ist von dualistischen Darstellungen zu unterscheiden, wie sie etwa der Film Metropolis im Bild der „doppelten Maria“ vorführt, siehe hierzu ausführlich: Eva Horn, „Die doppelte Maria. Weibliche Führerschaft in Fritz Langs Metropolis“, in: Staat in Unordnung?, hrsg. v. Stefan Krammer (Bielefeld: transcript, 2012), S. 25-46. Chamlams weibliche Führerfigur initiiert zwar wie die „echte Maria“ in Metropolis einen „Verweis auf etwas, das sie nicht selbst ist“ (Horn, 35). Bei Kronberg stiftet aber ,die strahlende Frau“ Harmonie und nicht wie die „strahlende Automaten-Maria“ des Films Zwietracht; ebenso wird Kronbergs Frau kein „Resonanzkörper eines Massewillens“ (Horn, 38), vielmehr steht der individuelle Bezug im Vordergrund.

117 Vgl. Kronberg, Ehud (Anm. 115).

118 Wallas, Kommentar zu Ehud, in: Kronberg, Werke II, 311.

119 Kronberg, „Chamlam“, 149. Vgl. ebd., 177-179.

120 Ebd., 176.

121 Ebd., 179.

122 Ebd., 135.

123 Ebd., 143.

124 Ebd., 169. 
weiteren Stufe auf seinem Weg, bei dem es um das beständige Enthüllen geht, so dass die Scham schließlich entweicht.

\subsection{Vokale als flüssiges Licht}

Chamlam strebt einer Verheißung zu, die nicht mehr an den Wechsel der Zeiten gebunden ist: „Nachts bin ich tot in Verheißung“, ${ }^{125}$ und die „Verheißung gleißt im Zenith“. ${ }^{126}$

Die Frage, die Kronberg bewegt, ist, wie aus den Spalten des Zerbrochenen eine neue Welt zu schaffen ist. Er verbindet dieses Ziel mit der Idee, eine neue Welt zu schaffen im Sinnfeld der Glorie. Mit den Stilmitteln des Expressionismus fallender Vokale löst sich deren dunkler und gedämpfter Klang in Lichtvisionen auf. Aus der Verflüssigung des Erstarrten bildet sich die Glorie aus flüssigem Licht. Chamlam beobachtet: „Von den Laternen fiel flüssiges Licht zum Putz, und ich klaubte es. “127 Die fallenden Vokale von a zum $u$ und zum Diphthong des ,au“ werden hier in der Lichtmetapher des „Lichtregens“ eingefangen und aufgehoben. Der Narr sammelt, um die Metapher weiterzudenken, den Lichtregen in seiner „Vokalschale“ - hier „au“ - und trägt sie nun in der Funktion des Dichters weiter in die Welt.

\section{Einer geht zum Zweiten: Die Umwandlung der Gespenster in die heiligen Laute des Alphabets, das Kraftzentrum „Beth“}

Die für die Gespenstergeschichte so wesentliche Teilung in Polaritäten überträgt Kronberg nicht nur auf seine Figuren, sondern in einen mystisch-religiösen Zusammenhang des „großen Beth“, auf die kabbalistische Deutung der Buchstaben als Kraftzentren. Die Gespenster werden bei Kronberg zur heiligen Wirklichkeit in den Lauten.

Im Motto zu Chamlam heißt es: „Einer geht zum Zweiten -.“128 Entsprechend beginnt die Erzählung mit einer Zweiteilung des Weges: „Ich bin im Aufgang, denn

125 Simon Kronberg, [Unbarmherzig blutet die Helle aus], in: ders., Werke I, 38 (zu Lebzeiten unveröffentlicht, Sept. 1915).

126 Simon Kronberg, [Eine weiße Möwe schick ich dir], in: ders., Werke I, 45 (zu Lebzeiten unveröffentlicht; Nov. 1915).

127 Kronberg, „Chamlam“, 156; ebenfalls in: „Chamlam erzählt Märchen“, 10, dort: „von den Laternen fällt flüssiges Licht zum Putz; ich glaube es.“ [Herv. R.S.].

128 Kronberg, „Chamlam“, 133. 
mein Weg wird von mir bewußt geteilt, Dank sei Gott, in einen beschützten, entsteinten, ebenen, frauenhaften und in einen anderen. “129 Zum „großen Beth“, das in den hebräischen Bibeln größer geschrieben ist als andere Buchstaben, erklärt Weinreb in Der göttliche Bauplan der Welt. Der Sinn der Bibel nach der ältesten jüdischen Überlieferung:

Diese große 2 wird uns verständlicher, wenn wir zurückdenken an unsere Betrachtungen des ersten Schöpfungsberichtes. Dort haben wir ja gesehen, daß die Schöpfung eigentlich eine „Zweimachung“ ist, die Entstehung der „Zwei-heit“. Beginnend mit „Himmel und Erde“, wird die Zwei-heit fortgesetzt in Licht und Finsternis. Die große 2 gibt daher an, daß alles, was darauf kommt, durch diese 2 bestimmt wird, bis etwas anderes kommt, eingeleitet durch einen anderen Beginn. Zudem will diese 2 sagen, daß nun der Teil anfängt, der vorher die „Eins“, der ungeteilte, allesumfassende Zustand der Harmonie in der „Ein-heit“ war. ${ }^{130}$

Chamlam durchläuft verschiedene Stufen. Erst als „der Betende“"131 kann er durch die Polarität, von der auch Bubers Daniel spricht, zu einer kurzfristigen Einheit finden; hier schließt sich Chamlam in das Gitter seines Selbst als ein ,vielfaches Umfangen“. ${ }^{132}$ Er gewinnt nach den Lauten ein neues Medium der Selbstfindung: den Tanz. Hier kann schließlich die Furcht von ihm abfallen: „Die Stille buchstabiert den Namen des oft Getäuschten. Bis das Ende in einem glücklichen Summen Abend aufgeht und Chamlams Hände der Furcht abfallen. Jetzt hat der Friede Raum zur Entfaltung. " ${ }^{133}$ In der Interferenz des Klangs kann er sich von der Angst befreien, die ihn bis dahin beherrscht hat, indem er sie sich vortanzt. ${ }^{134}$ „Chamlam zittert gering an diesem Abend. Seine Bewegungen entblättern. Ein kahles, neugeborenes und schon geprüftes Leben pulst in einem Raum. “135 Dieses Pulsieren formiert sich als „Protest gegen das herkömmlich Starke, sogar gegen das gewohnt Vollkommene“, wie Loerke erkennt. ${ }^{136}$ Es ist eine immanent aus dem Dasein hervorgebrachte „Neuerung“: „Seine Zukunft hält mitten in der

129 Ebd., 137.

130 Friedrich Weinreb, Der göttliche Bauplan der Welt. Der Sinn der Bibel nach der ältesten jüdischen Überlieferung, Übersetzung v. C. Schumacher, gekürzte Fassung (Zürich: Origo, 1966), 57-68. 131 Kronberg, „Chamlam“, 142.

132 „Er sieht die Menschen jenseits des Gitters nicht mehr. Er betastet sich. [...] Chamlam will einen neuen Weg“ (ebd.).

133 [sic!] Kronberg, „Chamlam“, 159.

134 Ebd., 168.

135 Ebd.

136 Oskar Loerke, „Rezension“, Berliner Börsen Courier vom 28. Mai 1922, zit. in: Bernhard Zeller, Expressionismus. Literatur und Kunst 1910-1923. Eine Ausstellung des deutschen Literaturarchives im Schiller-Nationalmuseum Marbach a. N. vom 8. Mai bis 31. Oktober 1960, Ausstellung und Katalog v. Paul Raabe u. H. L. Greve unter Mitarbeit v. Ingrid Grüninger (Marbach: Deutsche Schillergesellschaft, 1960), 275. 
Gegenwart.“137 Die Stufen, die Chamlam durchläuft, bieten nicht nur eine „Erregung der Fremdbegriffe“, ${ }^{138}$ sondern können zugleich als symbolischer Aufstieg durch den Sephiroth-Baum verstanden werden. Über die sechste Stufe, Tipheret, gewinnt er im Tanz die Frucht in der Fülle der Stille. Dann steht er vor der Prüfung der letzten fünf Stufen.

\section{Stufengang im Sephiroth-Baum: Das Erlebnis der Melodie im Strahl der Gottesglorie}

Auf dieser Stufe begegnet er einer Frau, die für ihn Klavier spielt, also den Klangraum öffnet, so dass er einen Moment der Ruhe findet.

Die Frau erhebt sich. Lange Schleier ihres Daseins ordnet jetzt Chamlam um sich, und alle tragen Farbe und Verstand wie eingewebt von jeher. Und da sie sich entfernt, behauptet sich Chamlam inmitten einer Straße, die sich überschlägt vor Mensch und Licht, in großer Stille. Er geht um einen großen Platz, als schlüge jeder seiner Schritte Lächeln um den Nächsten. So gewinnt Chamlam den Weg zu seinen Sinnen. ${ }^{139}$

Er gewinnt eine neue Hülle als „Schleier des Daseins“ in der Verwebung von Farben und Licht. Die Gewänder des Weiblichen geben seiner Seele ein Gewand. Im Schutz der langen Schleier der Königin bildet sich eine neue Lichtordnung. Diese zeichnet einen Weg der Sinnlichkeit vor, der die Welt des Todes auf den Kopf stellt, nämlich zur „Straße, die sich überschlägt vor Mensch und Licht, in großer Stille“. ${ }^{140}$ Kronbergs Darstellung ist ein „Salto mortale“, ein „Überschlag“ in die Sangeswelt der Psalmen, der Sprung führt in einen meditativ-religiösen Raum, dessen Stille (im liturgischen Rhythmus) seinerseits das Leben durchdringt und dynamisiert: „Der Kopf nickt zu [sic!] Sprung nach Sprung, wie Psalm zum Tun von Gott“, wie es in dem Prosagedicht „Kapitel“ (1917) heißt. ${ }^{141}$ Es ist diese „kosmische Gebärde“, ${ }^{142}$ die es dem Tänzer und Narren ermöglicht, seinen Weg zwischen Strahlen- und Schattenwelt fortzusetzen.

Wir haben eine doppelte Gebärde: Das weibliche Andere erwirkt nicht nur die lichte Höhe, sondern führt zugleich zu einem Wiedergewinn des Leibes. Die

\footnotetext{
137 Ebd.

138 Ebd.

139 Kronberg, „Chamlam“, 162.

140 Ebd.
}

141 Simon Kronberg, „Kapitel“, Die Aktion 7, H. 41/42 (1917), Sp. 558 (=ders., Werke I, S. 13).

142 Zur Bedeutung der kosmischen Gebärde aus der jüdischen Liturgie als Abschluss des Kaddisch und am Ende der Amida und Zeichen für einen „erfüllten Raum“ bei Kronberg siehe Hoffmann, Religiöse Turbulenzen, 61-62: 62. 
Richterin als die Andere ergreift von ihrem Betrachter, Chamlam, Besitz; dieser gibt aber gleichzeitig diese neue Hülle weiter, nämlich als „Gewand aus Worten am Morgen“. ${ }^{143}$ Damit ist eine neue Möglichkeit der Metamorphosen initiiert. Anders als der Protagonist bei Schmitz' Pepinster findet Chamlam über die Frau zu seinen Sinnen. Die mystische Konfiguration des religiösen Empfindens, das in der Lichtsymbolik zum Ausdruck kommt, bleibt also doppelt rückgebunden: zum einen an den Körper und dessen individuelle Erfahrung, zum anderen an eine Erfahrung von Leid, die in einer Verbindung mit dem Gespenstischen umgewandelt wird in die Möglichkeit einer Erneuerung. ${ }^{144}$

So erfährt Chamlam, was im Sohar steht, nämlich: „Wie der Seele ein Gewand gegeben ist, dass sie in dieser Welt bestehen könne, so wird ihr ein leuchtend Gewand höherer Art gegeben, um in jener Welt zu bestehen und in den Spiegel zu schauen, der aus jedem Land des Lebens sein Licht empfängt. “145 Kronbergs virtueller Raum zeichnet damit eine Art ideale Biografie im Spiegel des Anderen (der Frau). Als positive Erfahrung spektraler Weite führt sie zur mystischen Spekulation, in der sich der Sehende scheinbar auflöst. ${ }^{146}$ Interessanterweise ist diese Spiegelwelt sowohl lebendig als auch schemenhaft, geisterhaft. Damit hält Kronberg die Subjektivität des Protagonisten in der Schwebe und bereitet dessen göttliche Auflösung vor. Zugleich bewahrt er ihn doch vor der Vernichtung. Eine weitere Komponente kommt hinzu: die Musikalität des Wortes. In diesem „Klangbewusstsein“" ${ }^{147}$ kann sich das Ich neu finden: Chamlam wird einem „hohen Spiel“148 zugeführt, das er erst im letzten Teil ertasten kann. Er ist an einem Ort angekommen, wo er vergebens den Schatten sucht, ${ }^{149}$ dafür findet er zu einer inneren Sprache: „Kein Schrei mehr eilte über mich. “150 Die ursprüngliche Sprache seiner Jugend, „die ich erfand aus Weinen und Schreien““, ${ }^{151}$ ist überwunden.

143 Kronberg, „Chamlam“, 178.

144 Damit schärft er die religiöse Sinnlichkeit (,vivacity of religious sensitbility“), welche die Literatur des Expressionismus als solchen kennzeichnet, wie Hamilton und Renger zeigen, im Hinblick auf deren Lebendigkeit, vgl. Hamilton, John T. u. Almut Barbara Renger, „Religion, Literature, and the Aesthetics of Expressionism“, in: Aesthetics of Religion: A Connective Concept, hrsg. v. Alexander K. Grieser u. Jay Johnston (Berlin/Boston: Walter de Gruyter, 2017), 75-101: 89. 145 Ernst Müller, Der Sohar. Das heilige Buch der Kabbala, nach dem Urtext hrsg. von Ernst Müller (Wien: Glanz 1932), 158.

146 Vgl. Ralf Konersmann, Lebendige Spiegel. Die Metapher des Subjekts, überarb. und stark erw. Neuausg. (Frankfurt a. M.: Fischer-Taschenbuch-Verl., 1991), 88.

147 Hierzu weiterführend: Frank Krause, Klangbewußter Expressionismus. Moderne Techniken des Rituellen Ausdrucks (Berlin: Weidler, 2006).

148 Kronberg, „Chamlam“, 175.

149 Ebd., 176.

150 Ebd., 177.

151 Ebd., 135. 
Damit zeichnet Kronberg eine Befreiung aus dem Welt-Gefängnis des Gespenstischen nach, die zwar ähnlich beginnt wie die bekannten Gespenstergeschichten, aber zugleich darüber hinausführt, indem sein Tänzer und Narr auf Stufen zu einer neuen Erkenntnis springt.

Die Stufen, die er überwunden hat, führen 1.) über eine Geste der Furcht, symbolisiert im Abfallen seiner „Hände der Furcht“"152 in der überwältigenden Begegnung mit der „Richterin“, die ihm seine Einsamkeit nimmt; 2.) zu dem Erlebnis der Melodie und 3.) über eine Erfahrung der Starre als Equilibrium, welche die Erzählung schließlich einem neuen Lichtraum gegenüber öffnet (Kether). Es ist sein Stufengang durch den Sephiroth-Baum.

Die Erfahrung des Schmerzes seiner Umgebung transferiert und transzendiert Kronberg, bis sie für ihn eingelöst ist: „Ich kenne keine Umgrenzung mehr. “153 Es ist zugleich der Moment, in dem sich beides auflöst: Geschlecht und Körper. Das Selbst wird den Bedingungen von Raum und Zeit entzogen. Nur noch im Rückblick erscheint es eingrenzbar im Spiegel der vergangenen Stufen.

Kronbergs Schattenfiguren entgleiten ihrem Dasein in der Erfahrung des Schmerzes. Während für Döblins „Die Tänzerin und der Leib“ die Ermordung des Leibes das Kalte in der Welt hält, bedarf es des Zerschneidens des Ichs bei Kronberg, ${ }^{154}$ um zu einer Wärme zu finden. Chamlam muss immer wieder zerbrechen und sterben, um den „ersten Tag der Freude“"155 anbrechen zu sehen; aus dem „Garten der Zersplitterung“156 tritt er ein in das von „dünnen Häuten“ verschlossene Spiel. Dieses Zerreißen ist ein Opfer des Selbst und ein Ablegen der alten Hülle als einer Öffnung hin zum Unbegrenzten. ${ }^{157}$ Die Abspaltung der Wege ist damit auch ein Abblättern des vergangenen Lebens und ermöglicht die Resurrektion in eine neue Welt des Lichts: „Und wenn die Worte dennoch Dome der Verhinderung türmen, spalte sie von deinem Wege wieder ab!“"158 Die Abspaltung der Worte öffnet metaphorische Leerstellen, die Kronberg nutzt, um neue Choreografien im Sinne einer tänzerischen Einschreibung in den textuellen wie gelebten Raum zu ermöglichen. Chamlam kann als Schatten dem Körper in eine

152 Ebd., 160.

153 Ebd.

154 Ebd., 163. Vgl. Müller, Der Sohar, 133, zu Ps. 19.

155 Kronberg, „Chamlam“, 176.

156 Ebd., 163.

157 Vgl. Kronbergs unveröffentlichtes Gedicht [Der Tag neigt sich] (1938): „Der Glückliche. In ihrem Duft sucht er sich / findet er sich tief unter den Sternen. / Er, der sich erdreistet, ärmlich zu werden / reißt für seinen Blick endlich ihre Unendlichkeit auf“" (Simon Kronberg, [Der Tag neigt sich], in: ders., Werke I, 92).

158 Simon Kronberg, „Chasán” (1919), in: ders., Werke I, 180-209: 191. 
Sprache der Schmerzzonen entfliehen. Sie kreieren für die narrative Figur einen ihn umfangenden Raum.

Als „reine Gewalt“ entflieht er der Straße, die er mit weiblicher Kälte verbindet. Die Metapher des Frierens wird zum Attribut der anderen Seite seiner Existenz, die er dichterisch überwindet. So formt Kronberg die Stadt zu „strahlenden Sätzen“, wie er es in einem Tagebucheintrag erklärt: Während die eine Seite in „Schmerzen zuckt“, gilt für die andere: Sie „feiert Feste und die elektrischen Straßenbahnen illuminieren Erlebnisse. Posaunen sind die Worte, die mir zugeboren werden aus Tätlichkeiten, sie formen sich zu strahlenden Sätzen; es bedarf nur noch der Melodie eines köstlichen Frauenlächelns, und in sich geschlossen ist die Sinfonie Berlins. “" ${ }^{159}$ In der Wirklichkeit des Licht-Klangs als reiner Bewegung wird eine innere Einkehr jenseits der Körper und Spektren möglich, wird das „hohe Lied” hörbar.

\section{Tanz als Hüter der Expression: Aus der Einung im Klang zum Licht einer neuen Welt}

Auf seinem Weg der Zwei („Beth“) kann Chamlam die Einheit, die die Kabbala durch den Begriff des Jichud als „Einung“ ausdrückt und die zugleich der Inbegriff des Friedens und der Versöhnung ist, ${ }^{160}$ erst finden, sobald die Gewalten des Lebens von ihm schwinden. Einzig die Bewegung als Geste und als Tanz bleibt. So hütet ihn die Bewegung. „Tod wurde umzeichnet von deinem einzigen Wort und abgetragen in eine Form, die jetzt dein schlafender Freund ausfüllt. Ich aber, die Bewegung [Herv. d. Orig.], die sich dir stetig mitteilt, bin an dir, und du hütest mich.“161 Das ist der Moment seiner getanzten Gebete aus „verbranntem Lachen“. ${ }^{162}$ Chamlam muss zerreißen, dann erst kann die Geste ihn

159 Kronberg, Tagebuch vom 1. September 1915, zit. nach: Armin Wallas, „Nachwort”, in: Kronberg, Werke II, 335-410: 367. Anders als Walther Ruttmann in seinem späteren Film „Berlin - die Sinfonie der Großstadt“ (1927) präsentiert Kronberg hier eine transsinnliche Wendung, die das Oszillieren der Eindrücke der Großstadt überwindet. Ruttmanns Film dagegen löst die Spannungen der Großstadt und der darin repräsentierten Moderne nicht auf, wie Derek Hillard gezeigt hat, s. Derek Hillard, „Walter Ruttmann's Janus-faced View of Modernity: The Ambivalence of Description in ,Berlin. Die Sinfonie der Grossstadt““, Monatshefte XCVI.1 (2004), 78-92: 91. Ruttmann wie Kronberg nutzen allerdings beide Verfahrensweisen, die die herkömmliche „FabulaStruktur“ auflösen (,Its story consists of the oscillation of light to darkness and activity to inactivity that the city as the film's character embodies“ [84]).

160 Ernst Müller, Der Sohar und seine Lehre, 3. erw. Auflage (Zürich: Origo 1969), 82.

161 Kronberg, „Chamlam“, 174.

162 Simon Kronberg, „Nacht”, Die Aktion 6 (1916), H. 24/25 (=Karl Jakob Hirsch Heft) (=ders., Werke I, 9). 
erlösen. ${ }^{163}$ Kronbergs performativer Expressionismus verbindet sich mit einer religiösen Vision und wird so transsinnlich. Das heißt: In der Bewegung als Mitteilung eröffnet sich ein performativer Akt, der religiös deutbar wird, nämlich als Dialog mit dem Göttlichen. Das gedichtete Wort als Gesprächsbewegung und Handlung wird zum Hüter eines den Tod transzendierten Traums, der schließlich in das Leben der an Hiob erinnernden Erzähler-Figur eingreift und dieses verändert.

Das erste „Licht der Freude“164 lässt den Körper in sich ruhen. Was Chamlam in seinen Metamorphosen erreicht, ist, einen „Körper ohne Vorgang“165 zu treffen, der einst als „leuchtende Verheißung“ begann. Im Rückblick wird noch einmal der Verlauf der Erzählung erklärt. So sagt die Frau:

Er aber, die Gewalt, ging meinen Forderungen nach und erhaschte, weit von sich und Gedanken, was mit ihm vor mir stand:

etwas von meiner ersten Furcht

etwas von meiner ersten Melodie

etwas in der ersten überaus leuchtenden Verheißung. ${ }^{166}$

Es ist der Moment, in dem Chamlam zum Körper ohne Geschlecht wird, nämlich Teil einer ,aushorchenden Liebe“. ${ }^{167}$ Nun horcht er, ebenso wie die Frau, die ihm

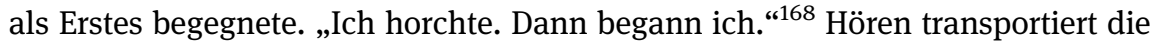
zentrale jüdische Kernbotschaft: Sch'ma Israel. ${ }^{169}$ Bei Kronberg ist Gott in seiner Erscheinung auch „die Frau“, nämlich „eine Horchende“ ${ }^{170}$ Während Chamlam die weibliche „Güte“"171 für kurze Zeit begleitet, kann Klang walten. Chamlam hat also im Tanz zur Einheit mit „der Horchenden“ gefunden. Für ihn ist es „,[]er erste Tag der Freude“. ${ }^{172}$

Kronbergs Erzählung endet in einem strahlenden Moment des Geistertanzes, aber unter der Leitung der Elohim: „Solange die angesagten Worte tänzeln, ist der Richter angenehm zu sehen und der Auferstandene bequem. “173 Zeit weitet sich zum Raum. ${ }^{174}$ Die Gebärde, die die Schale der Welt öffnet, wird möglich. Hier

163 Kronberg, „Chamlam“, 166.

164 Ebd., 176.

165 Ebd., 177.

166 Ebd., 178.

167 Ebd., 179.

168 Ebd., 173.

169 Vgl. hierzu ebenfalls Hoffmann, Religiöse Turbulenzen, 115.

170 Vgl. Kronberg, „Chamlam“, 138.

171 Ebd., 134.

172 Ebd., 176.

173 Ebd., 179.

174 Vgl. ebenfalls Simon Kronberg, [Abschied] (zu Lebzeiten unveröffentlicht, 1925), in: ders., Werke I, 87. 
entbirgt sich die Kawwana, die Intention, wie es Buber erklärt, und die bereits im Chamlam angelegt war:

Kawwana ist ein Strahl der Gottesglorie, der in jedem Menschen wohnt und die Erlösung meint. Dies aber ist die Erlösung, daß die Schechina aus der Verbannung heimkehre: „Daß alle Schalen von der Gottesglorie weichen und sie sich reinige und sich eine ihrem Eigner in vollkommener Eignung.“ Des zum Zeichen erscheint der Messias und macht alle Wesen frei. ${ }^{175}$

Die zentralen Stichworte sind dabei: Farbe, Fließen, Licht. Die bei Kronberg immer in Lächeln und Farbe gekleidete Frauengestalt dieser Verheißung ${ }^{176}$ opponiert dem Schmerz - „Schmerz ist eine Frau des grauesten Tages“. ${ }^{177}$ Wenn aber der Sephiroth-Baum erblüht, „tanzen tausend Kronen“. ${ }^{178}$ Während im Schmerz die Gefäße zerspringen (Schewirat he-kelim) offenbaren sie den unbegrenzten Gott, En Sof. Die Schechina ist aus der Verbannung befreit.

\section{Initiation. Sprache in den Falten der Stille: Tanz der Schechina}

Das Ziel seiner Reise wird als Initiation erfüllt durch die Erfahrung einer pneumatischen Geistersprache, die in der Stille sichtbar wird: die Frau spricht „in den Falten der Stille“: ${ }^{179}$ „Kein Schrei mehr eilte über mich.“180 Dieses Verstummen ist ein zentraler Aspekt von Kronbergs Sprache. Im Rückblick verbindet sich das Leben Chamlams mit dem dieser ihn begleitenden Richterin, bis nichts mehr bleibt als ein „warmer Wind“ - Ruah: „Und ein Mensch und noch einer finden zuselbst [sic!] über trübe Treppen des Gerichts ... Ein warmer Wind in der Straße lief wie ein Dank. “181 Dieser Wind als Hauch Gottes ist Ruah, die Seele als Wesensglied des

175 Martin Buber, „Der Sinn der chassidischen Lehre“, Neue Blätter 3, H. 1/2, Buberheft (1913), 46-60. 176 „Die Frau ist in sich Farbe freudig“(Simon Kronberg, „Die Frau“, in: ders., Werke I, 59-60: 59); „Woher kamen die Farben? Von dem Lächeln einer Frau“ (Kronberg, „Chamlam“, 152).

177 Simon Kronberg, [Als eine Blüte fiel], in: ders., Werke I, 49 (zu Lebzeiten unveröffentlicht, ca. 1916-1918).

178 Simon Kronberg, [Das Angesicht der Liebe], in: ders., Werke I, 115 (zu Lebzeiten unveröffentlicht, 1946).

179 Vgl. Kronberg, „Der Jude“, 27.

180 Kronberg, „Chamlam“, 177.

181 Ebd., 179. 
Menschen. Dies ist die Selbstbegegnung und Auflösung der Schattenfiguren im Bild des flüssigen Lichts, das sich im Tempel bricht und zum „Wind der Winde“ erweitert: „Wind der Winde findet seinen letzten Ort.“ ${ }^{182}$ Es ist der Ort, an dem das „hohe Spiel“183 als Geheimnis des Lächelns zu einer Geistsprache wird, zum „Gespräch“:: ${ }^{184}$ „beide bedienen die Stille“. ${ }^{185}$ Hier löst Kronberg die „Körper ohne Geschlecht“ in einer Lichtmetapher auf: „wir sind der beginn einer welt mit lichtigen geschöpfen. “186 Damit kann er die Einsamkeit der „unkörperlichen Schatten“, ${ }^{187}$ wie sie Ehrensteins Tubutsch beschreibt, überwinden.

Chamlam findet durch seine Reise durch die Straßen der Stadt, durch ein Spiel von Fesselung und Entfesselung im Bruch der Körper schließlich das geheimnisvolle Spiel der Hüllen und einen Ort, an dem die Richterin als Schechina tanzt, die „scharlachrote Blüte“: ${ }^{188}$ Sie ist die symbolische Richterin und eine Zeitlosigkeit der Liebe. Die Schale, das „Gewand aus Andacht zu Abend“, ${ }^{189}$ wandelt sich zum Klangraum und zur Möglichkeit einer „Atemwende“, um Celans Begriff vorzugreifen. Das Gedicht gewinnt dabei die Funktion eines theatralen Sprachraums „inmitten Trümmer und Blickgewimmel“, ${ }^{190}$ der jedoch das Schattenspiel transzendiert:

Ich war die Nacht und schöpfte aus mir

[...]

Und in das Abteil eines hüllenden Stücks Himmel

stieg in Helle ich und blieb gefaltet

und die Mutter kam und Müdes spaltet

inmitten Trümmer und in Blickgewimmel. ${ }^{191}$

Das Innere des Wortes ist zur Geste im Tanz geworden und kann so als Seele entweichen. Bei Kronberg löst sich die expressionistische Gespenstergeschichte auf. Der Schatten wird zur „überaus leuchtenden Verheißung““192 eines eigenen

182 Kronberg, „Der Jude“, 27.

183 Kronberg, „Chamlam“, 175.

184 „Die Frau hört auf zu spielen, sieht nach ihm und lächelt. Chamlam lächelt wieder. Das ist ein Gespräch“ (Kronberg, „Chamlam“, 160).

$185 \mathrm{Vgl}$. „wir stehen still. wir beide bedienen die stille“ (Simon Kronberg, libe 'nju, in: ders., Werke I, 130), ebenso: Kronberg: Schimen in der Stille, 5. Szene, in: ders., Werke II, 25.

186 Kronberg, libe 'nju, 130.

187 Ehrenstein, Tubutsch, 54.

188 „An den Wänden entlang schleiche ich und versuche, eine scharlachrote Blüte zu fassen, die vor meinen Augen entstand und nun tanzt“ (Kronberg, „Chamlam“, 157).

189 Ebd., 179.

190 Simon Kronberg: [Es war einmal], in: ders., Werke I, 84 (zu Lebzeiten unveröffentlicht, 1921).

191 Ebd.

192 Kronberg, „Chamlam“, 178. 
Seins aus den Falten der Stille. Sprache begegnet der Gewalt und besänftigt sie, nämlich im Licht-Gewand ihrer Gesten - „schattenvoll““. 193

\section{Fazit}

Der kontextlose Klang der Sprache und ihre Magie überwinden in Kronbergs Texten die Gewalt der Stadt und balancieren sie aus durch die Gewalt des Lichts. Sinnlichkeit wird sakralisiert und in Metaphern des Diaphanen zu einer transzendenten Ganzheit verbunden. Im geheiligten Klang der Sprache findet das Alpha zum Beth, zur neuen Einheit. Im Wirbel des Tanzes gewinnt Kronbergs Narr den „geweihten Ort“. 194

Damit kreiert Kronberg einen Gegenort zur Gespenster-Stadt der Expressionisten. Hier zeigt sich seine Sonderstellung in der deutschen Literatur des Expressionismus: Die als erstarrt empfundene Welt wird in der leiblichen Metaphorik neu dynamisiert. Während die Texte von Döblin, Ehrenstein und Schmitz kritisieren, dass die Welt der Maschinen den Körper in die Arena der Zwecke und technischen Ratio wirft, unterläuft Kronberg dieses Schema. Er nutzt die Zersplitterung des Körpers, um ihn in eine neue, teils surreale Performanz zu setzen. Seine Schattenfiguren nehmen die Wirklichkeit in eine spektrale Welt mit und initiieren eine Wandlung der Körper. Auf diese Weise gestaltet er eine mystisch inspirierte (Selbst-)Verwirklichung, die zur Basis eines gemeinschaftlichen Lebensethos wird und einen Gegenpol zur expressionistischen Entäußerung bildet. Zentrale Bedeutung erhält dabei die Begegnung mit der Figur der namenlosen Frau als Allegorie von Weisheit, Liebe und Geborgenheit. Seine auratische Lichtfigur ermöglicht eine weltimmanente Erfahrung des Ich-Erlebens und führt auf eine Mikroebene der Sprache und der Buchstaben, die als Kraftzentren deutbar werden.

In der sprachlichen Auseinandersetzung mit Emotionen der Angst, Scham und Überwältigung wechseln Kronbergs Protagonisten in eine Welt der Rhythmen. Seine Konzeption von Sprache als einem mystischen Klangraum, in dem Schattenfiguren tanzen, verbindet religiöse Praxis und Performanz $\mathrm{zu}$ einem transsinnlichen Expressionismus. Kronberg verbindet also religiösen und performativen Expressionismus und findet $\mathrm{zu}$ einer eigenen Form des Transsinnlichen. Leben und Schreiben verschränken sich zu einer essenziellen Kulturtechnik der Selbsterfahrung. Lesen wird zum aktiven, konstruktiven Prozess der Teilhabe am kabbalistisch-mystischen Geschehen und an der Einung des Ichs.

193 Ebd., 143.

194 Simon Kronberg, „Der Tanzende. Eine Legende“, in: ders., Werke I, 336-339: 339. 
Damit entfernt er sich von seinen Zeitgenossen. Aus seiner literarischen Konfrontation mit dem Gespenstischen seiner Gegenwart erwächst ein produktiver (Traum-)Dialog, der in das Leben zurückwirkt und sich als mystische Konfiguration des Glanzes im Gebet realisiert. Dies ist als Aufstieg durch den SephirothBaum symbolisiert. Seine stummen Sprechakte eröffnen diaphane Räume und metaphorische Leerstellen im Zeichen des Gedenkens und für eine neue Form der Besinnung in der doppelten Bedeutung von Sinn und Sinnlichkeit. So erwirkt Kronbergs sprachliche Reise durch die sakral erlebte Topografie der Stadt die Erfahrung einer pneumatischen Geistersprache, die im Schattenraum jene Sätze bildet, die sich im Lichtraum als kosmische Gebärde im Spannungsfeld von Körper und Leid äußern und im Klangkörper der Texte als Aufzeichnungen seines spezifischen Expressionismus resonieren. 